\title{
LA BIBLIOTECA DEL COLEGIO SAN BERNARDO DE LA COMPAÑIIA DE JESÚS EN OROPESA (TOLEDO)
}

\author{
POR \\ RAMÓN SÁNCHEZ GONZÁLEZ \\ Departamento de Historia. Universidad de Castilla La Mancha
}

\section{RESUMEN}

Don Francisco Álvarez de Toledo, virrey del Perú fundó en 1578 en su villa natal de Oropesa un colegio en el que se impartirían tres enseñanzas, GramáticaLatinidad, Artes y Teología que puso bajo la tutela de la Compañía de Jesús y cuya existencia perduró hasta la expulsión de los jesuitas en 1767. Uno de los rasgos más notables del centro educativo fue su biblioteca general que superaba los 2.000 títulos y que, en contra de lo que fue habitual, pasó a propiedad de los descendientes del fundador, patronos a su vez de la fundación. Gracias a la existencia de un completo y pormenorizado inventario se presenta en este trabajo un análisis de diferentes aspectos relacionados con la historia cultural en relación con el mundo de los libros.

PALABRAS ClAVE: Historia cultural, cultura escrita, libros, Compañía de Jesús, siglo XVIII, aristocracia

\section{THE LIBRARY AT ST. BERNARD'S SCHOOL OF THE SOCIETY OF JESUS IN OROPESA (TOLEDO)}

\begin{abstract}
Don Francisco Álvarez de Toledo, viceroy of Peru, founded a school where Grammar- Latin Studies, Arts and Theology were taught in his hometown of Oropesa in 1578. The Society of Jesus was entrusted with the school and it endured through time until the expulsion of the Jesuits in 1767. One of the most outstanding characteristics of the educational institution was its general library which contained over 2,000 volumes. The library, contrary to the custom of the time, was inherited by the descedants of the founder, patrons in turn of the foun-
\end{abstract}


dation. Thanks to the existence of a complete and detailed inventory, this article analyses different aspects related to cultural history as far as books are concerned.

KEY WORDS: Cultural history, written culture, books, Society of Jesus, 18th century, aristocracy

Recibido/Received 14-04-2009

Aceptado/Accepted 21-09-2009

En 1578 don Francisco Álvarez de Toledo, virrey del Perú, ${ }^{1}$ título con el que pasaría a la posteridad, miembro de una de las familias más encumbradas de la nobleza castellana, la Casa Condal de Oropesa, decidió mediante testamento redactado y signado en Los Reyes (Perú) fundar un colegio - «es la principal obra que yo pretendo»- animado por el espíritu del Concilio de Trento que «manda se hagan colegios seminarios para sacar de ellos plantas para la Iglesia», bajo la advocación de san Bernardo en su villa natal de Oropesa cuya tutela encomendaría a la Compañía de Jesús. Generosamente dotado con dineros y propiedad rústica y urbana, albergó 33 colegiales cristianos viejos durante cuya permanencia eran instruidos en tres facultades: Gramática-Latinidad, Artes y Teología.

Se puso en marcha con muchas desavenencias, contratiempos y diferencias entre los deseos del fundador y las exigencias de los jesuitas. Las negociaciones recorrieron un largo y tortuoso camino salpicado de dificultades. Pasaron por fases muy heterogéneas, desde la coincidencia aparente, que hacía presagiar un pronto inicio de las actividades docentes, hasta la irritación profunda por la intransigencia de las partes, sin desdeñar incluso la opción de entregar la fundación a otra orden religiosa.

Superados los obstáculos iniciales e instalados en una cómoda rutina, solo se quebró por alguna novedad como su interrupción en un breve tiempo, otro «cese temporal de la convivencia» entre patronos y Compañía de Jesús, o la ampliación de estudios con la creación en 1629 de una Escuela de Primeras Letras. El colegio de san Bernardo fue, durante más de dos siglos y medio, una referencia fundamental para la educación de jóvenes del señorío y estado de Oropesa. ${ }^{2}$

Además de los diferentes recursos, humanos y materiales de la institución, su biblioteca fue el complemento imprescindible de una educación eficaz. Y

${ }^{1}$ Robert Levillier, Don Francisco de Toledo. Supremo organizador del Perú. Su vida, su obra (1515-1582). Años de andanzas y de guerras (1515-1572), 2 vols., Madrid, Espasa-Calpe, 1935; Don Francisco de Toledo. Supremo organizador del Perú. Anexos inéditos. Memoriales, cartas, testamento, \&, Madrid, Espasa-Calpe, 1935. León Gómez Rivas, El virrey del Perú Don Francisco de Toledo, Toledo, Instituto Provincial de Investigaciones y Estudios Toledanos 1994.

${ }^{2}$ Un estudio exhaustivo sobre el colegio y el resto de fundaciones supervisadas por los jesuitas puede leerse en mi libro La Compañía de Jesús y Oropesa, Toledo, Ayuntamiento y Diputación Provincial 2009, al que nos remitimos evitando así las reiteraciones.

Hispania Sacra, LXIII

127, enero-junio 2011, 41-74, ISSN: 0018-215-X 
hasta puede decirse, un elemento consustancial a una formación de calidad. Sus libros almacenaban todos los saberes. Así debieron pensar los jesuitas y, conscientes de su trascendencia, dejaron algunos patrimonios bibliográficos que despiertan admiración.

Bartolomé Martínez ha escrito páginas atractivas sobre las librerías y las imprentas jesuitas. ${ }^{3}$ Las tenemos en cuenta junto con las aportaciones de otros autores. El origen y la creación de las bibliotecas son muy variados. Generalmente va incluida una partida en la carta fundacional de la institución, incluso se estipula una renta anual para adquirir obras, y con frecuencia se completa con aportaciones procedentes de donaciones particulares, ${ }^{4}$ de las bibliotecas privadas de los propios religiosos o con manuscritos no publicados, fruto de sus inquietudes intelectuales y de sus reflexiones en torno a la predicación y a las cuestiones teológicas más candentes.

Desde sus comienzos, la Compañía de Jesús, a través de las Constituciones y de la Ratio studiorum, ya puso de relieve la exigencia de librerías en sus establecimientos educativos y la necesidad de destinar una renta para su incremento continuado que permitiera configurar una completa colección de obras y actualizar los conocimientos. ${ }^{5} \mathrm{La}$ importancia que daban a los libros explica las numerosas imprentas que crearon. En Toledo se estableció una en 1591. En la época ilustrada se incrementaron notablemente, pero su número fue limitado y su influencia discreta, aun siendo un símbolo del culto a la letra impresa. Por sus prensas pasaron obras de tema eminentemente piadoso y humanista, muchas se convirtieron en los manuales en sus centros de estudios. Predominaron los de formación religiosa. Por eso, existió una clara restricción a la hora de adquirirlos, pues estaban sometidos a la censura férrea establecida de la Congregación del Índice y a la diocesana. Bartolomé señala que había tres tipos de autores: vitandos, prohibidos y conflictivos. Los vitandos, con los que había que tener una actitud precautoria, eran Erasmo, Vives, por cuestiones ideológicas y religiosas, y Terencio por problemas de moralidad; los prohibidos eran los condenados por herejía o por sus ideas peligrosas, contrarias a la doctrina de la Iglesia; los conflictivos procedían de la censura oficial.

\footnotetext{
${ }^{3}$ Bernabé BARTOlomé Martínez, «Las librerías e imprentas de los jesuitas (1540-1767): una aportación notable a la cultura española», Hispania Sacra XL/81 (1988) pp. 315-388.

${ }^{4}$ Antonio Borrás Feliú, «Fundación del colegio de la Compañía de Jesús en Huesca (15951625)», Hispania Sacra XXXII/65-66 (1980), pp. 59-87. En 1607 el canónigo de Zaragoza, doctor Pedro Arguedes dejó al colegio su biblioteca valorada en 700 escudos.

${ }^{5}$ Es sintomático que la biblioteca de Oñate, un centro de «ínfima categoría» evidencia un conjunto de obras valioso por su cantidad y calidad. Ignacio ZuMALDE, «El traslado del Colegio de los Jesuitas de Oñate a Bergara en el siglo XVI», Boletín de la Real Sociedad Bascongada de los Amigos del País, vol. XLI/3-4 (1985), pp. 757-793. Si esto ocurría con un colegio de escasa relevancia es fácil imaginar lo que sucedería en otro de categoría superior.
} 
La organización de las bibliotecas seguía un patrón. Bajo la supervisión del padre prefecto de librería, auxiliado por algún hermano librero, se ordenaban y colocaban casi siempre por orden alfabético y según facultades y materias. Estaba reglamentada la limpieza de la habitación y de los libros y se admitían los préstamos y servicios, con el permiso del rector.

Las colecciones fueron el germen de bibliotecas sobresalientes, como la del colegio de Manresa, ${ }^{6}$ otras universitarias y diocesanas. Hubo otros centros que carecían de ellas si bien los padres que estaban en ellos tenían libros propios, como sucedía en Albacete ${ }^{7}$ o Motril. ${ }^{8}$

En el colegio de San Bernardo de Oropesa, en el testamento fundacional, hay tres cláusulas referidas a los libros. En una, se dan 1.000 ducados «para que se compren con ellos libros para la Librería de la Compañía». Otra ordena «que de los 450 ducados de renta, los cincuenta han de quedar perpetuamente consignados para la dicha librería sin poderlos convertir en ninguno otro uso» y finalmente dispone que los textos personales que donó «no se han de poder sacar en ninguna manera, ni por causa alguna, en ningún tiempo, del dicho Colegio».9

En fecha tan temprana como 1590 el padre Juan Legaz escribe al patrón de San Bernardo diciéndole que dejó en su poder una memoria de los libros que se llevaron al colegio de Talavera certificando que se devolverían al de Oropesa. ${ }^{10}$

Años después, 1607, el titular del señorío se interesa por saber si se ha gastado dinero en obras impresas, si se están empleando los cincuenta ducados asignados y si se ha obtenido patente del Padre General para que no se saquen del colegio. ${ }^{11}$

\footnotetext{
${ }^{6}$ Antonio BorRás Feliú, «Establecimiento de los jesuitas en Manresa, según los documentos del archivo general de la orden de Roma (1599-1638)», Miscelania d'Estudis Bagencs 3 (1984), pp. 169185. En 1625 se inician las obras del colegio e inmediatamente se hacen las primeras entregas de libros dando «l'inici de la que, al cap d'uns anys, sería famosa biblioteca».

${ }^{7}$ María Dolores García Gómez, Memoria de unos libros: la biblioteca de los jesuitas expulsados del Colegio de Albacete, Albacete, 2001. Aquí no existía una biblioteca para uso común, los libros que estudia son los que cinco padres tenían en sus respectivos aposentos. En total juntaban 545 registros -de libros impresos y papeles manuscritos-correspondientes a 279 autores. Un avance de este trabajo en María Dolores GARCía GóMEZ, «La biblioteca del colegio de jesuitas de Albacete en el trance de la expulsión (1767)», Hispania Sacra LII/105 (2000), pp. 229-258.

8 Julián J. LOZANO NAVARRO, «El expediente de incautación de temporalidades del colegio de San Luis Gonzaga de Motril: los libros de los jesuitas de un colegio del Reino de Granada en 1767», Chronica Nova, 27 (2000), pp. 285-304. El trabajo estudia la parte del expediente de incautación de temporalidades correspondiente al inventario de los libros que pertenecían a los cinco padres que trabajaban en el colegio. La mayoría de ellos son de tipo religioso: sermones, honras fúnebres, temática mariana, casi todos del siglo XVIII e impresos en ciudades andaluzas. Había 57 manuscritos y 298 impresos.

${ }^{9}$ A.H.N. Sección Nobleza, Frías C. 1288, D. 7.

10 A.H.N. Sección Nobleza. Frías C.1290, D. 39/4.

${ }^{11}$ A.H.N. Sección Nobleza. Frías C.1290, D. 11.
}

Hispania Sacra, LXIII

127, enero-junio 2011, 41-74, ISSN: 0018-215-X 
En un memorial sin fecha se alude a que son necesarias para los colegiales de Artes «todas las obras de Aristóteles con algún buen comento sobre ellas», amén de media docena de candiles con sus veladores y becas. ${ }^{12}$

Cuando se produce la expulsión en 1767 proliferarán las noticias. Carlos III dicta dos provisiones legales que tienen relación con la cultura escrita. La Real Cédula de Provisión de 22 de abril de 1767 con una «Instrucción de lo que se deberá observar para inventariar los libros y papeles existentes en las casas que han sido de los regulares de la Compañía en todos los dominios de S. M.» que contiene instrucciones sobre la clasificación y confección de índices y la «Real Provisión de los Señores del Consejo en el Extraordinario a consulta de S. M. en el que se incluye la Instrucción formada sobre el destino de todas las librerías existentes en las casas, colegios y residencias...» de 2 de mayo de 1772 .

A estas providencias se añade la Real Cédula de 17 de febrero de 1771 promulgada por la Corona para crear, con los libros de los centros jesuíticos, bibliotecas episcopales en las capitales de cada diócesis. En virtud de esta última, la de Oropesa pasó al obispado de Ávila, pero la duquesa de Huéscar, como patrona, obtuvo una certificación, dada en Madrid a 13 de octubre de 1772, por la que se le reintegraba bajo el argumento de «no deber ser comprendida la librería de ese que fue colegio de regulares en la aplicación general mandada hacer para biblioteca episcopal en la capital de la diócesis, mediante haber sido comprada y aumentada con caudales de las expresadas Memorias y obras pías». ${ }^{13}$

Resultado de todas estas instrucciones legales fue que la extraordinaria biblioteca de los jesuitas pasó a manos del titular del condado ${ }^{14}$ por su condición de patrón y por haber instituido el centro su ascendiente don Francisco de Toledo, virrey de Perú. Gracias a esto, se dispone un magnífico inventario, ${ }^{15}$ confeccionado en 1768 en Oropesa por Nicolás Antonio de Malla Carvajal y Posse que demuestra su magnitud y su calidad. Se recuerda que el virrey, cuando fun-

12 A.H.N. Sección Nobleza. Frías C.1291, D.1

13 A.H.N. Sección Nobleza. Frías C.1288, D. 16, fol. 2.

${ }^{14}$ Sobre el origen y el interés de la nobleza castellana hacia el mundo de los libros puede leerse Ramón SÁNCHEZ GONZÁLEZ, «Patrimonio bibliográfico y cultura escrita en la aristocracia castellana de la Edad Moderna», I Jornadas sobre Patrimonio Bibliográfico en Castilla-La Mancha, Junta de Comunidades de Castilla-La Mancha, 2004,pp. 73-120.

15 Para hacerse una idea de la precisión con que fue elaborado cito la referencia de la primera obra anotada: «Libro en octavo con el título Los dos libros de las epístolas selectas de Marco Tulio Cicerón, en que se pone el uso de Cartas narratorias y de favor llamadas comendaticias puestas con traducción y declaraciones en lengua castellana, hechas por el maestro Pedro Simón Abril profesor de Letras humanas y Philosophia, natural de Alcaraz y Catedrático en la insigne universidad de Zaragoza. Autoris ad Lectorem tetrastichon. Olim quod solitum es numeroso tempore disci. En potes exiguo querere lector habe. Nam tibi dat parvo presens volumine charta. Quod tullit eloquio lingua latina suo. En Zaragoza por Juan Soler impresor de libros, año mil quinientos ochenta y tres. Con privilegio, véndese en casa de Luis Ganeiro, a la Cuchillería». 
dó el colegio, «entre una de las fincas que dio e hizo fue para el aumento y conservación de la librería: y con motivo de haberse comunicado orden general para que todas las de los regulares se pusiesen a disposición de los Reverendos Obispos para que sirviesen de pública Biblioteca a los respectivos diocesanos, representó el Comisionado de las Temporalidades de Oropesa, sobre cual de las providencias debía cumplir... y V.A. se ha servido declarar pertenecer y deberse entregar a mi parte... por haber sido comprada y aumentada con fondos de las memorias y obras pías del virrey don Francisco Álvarez de Toledo».

El «Inventario y índice de los libros del colegio de Oropesa, los cuales están colocados por alfabético ${ }^{16}$ y numerados en cumplimiento de lo prevenido en la Real Instrucción de 23 de abril de 1767», consta de 2.279 registros de diferentes formatos, muchos en latín y otros en romance, más «otro libro de a folio de marca forrado en cabritilla encarnada que se compone todo de mapas». Continúa con otros 16 registros de «Libros sin forro, principio ni fin; medios libros y pedazos de otros, hallados en la alacena que está en la librería de este colegio» -vocabularios, breviarios, biblias...-, 5 manuscritos, más los 97 volúmenes que se hallaron en la casa que en Jarandilla alberga al colegio. En síntesis, podemos establecer unas cifras de 2.376 registros y 3.281 volúmenes, exclusivamente biblioteca general, ${ }^{17}$ sin computarse los existentes en los aposentos de los padres de la Compañía allí instalados. ${ }^{18}$

Comparados con el de otros centros regidos por jesuitas, ${ }^{19}$ el conjunto bibliográfico de Oropesa es de una cuantía intermedia, inferior a los colegios de Salamanca, Granada, Murcia o de ciudades populosas, pero muy superior al de entidades de población similar a la suya. ${ }^{20}$

16 Con todo, el índice alfabético del inventario no es totalmente riguroso. A título de ejemplo digamos que Pomponio Mela figura en la M de Mela y en la P de Pomponio; sucede lo mismo con Alonso Díaz de Montalvo, en la D y en la M.; igual con Salustio en la S y en la C de Crispo.

${ }^{17}$ A.H.N. Sección Nobleza Frías C.1296, D.1 y C.1297, D.1

18 Don Nicolás Antonio en una certificación que emite en Madrid con fecha 19 de septiembre de 1774 aclara que además del índice copiado, que queda en la Escribanía de Cámara a su cargo, tiene otro de los libros encontrados en los aposentos de individuos del mismo colegio. Su paradero nos es desconocido así como su contenido, pero, por bibliografía comparada, podemos afirmar que su relevancia no sería nada desdeñable, pues era frecuente que los religiosos acumularan bastantes libros en sus habitaciones. Javier VERGARA CIORDIA, «El proceso de expropiación de la biblioteca de los jesuitas en Pamplona (1767-1774)», Revista de Historia Moderna. Anales de la Universidad de Alicante 26 (2008), pp. 325-342. De los aproximadamente 6.000 volúmenes que conformaban esta biblioteca, casi por mitad están divididos entre librería común y estancias de los sacerdotes de la orden.

${ }^{19}$ En el artículo de Constancio EgUía RuIZ, «Los jesuitas proveedores de bibliotecas», en Razón y Fe 130 (1944), pp. 235-258 pueden hallarse algunos datos concretos de colegios, así como en José Luis Betrán Moya, «Bibliotecas de Ultramar: la biblioteca del Colegio de San Luis de Potosí de la Compañía de Jesús en Nueva España en el momento de la expulsión», en El mundo urbano en el siglo de la Ilustración I, Santiago de Compostela, 2009, pp. 307-320.

${ }^{20}$ El colegio de Salamanca tenía 12.000 volúmenes, el de Granada 10.555 obras (29.483 vols.), el de Murcia 3.724 registros, (M ${ }^{a}$ Victoria Játiva Miralles, Biblioteca del colegio de San Esteban de los

Hispania Sacra, LXIII

127, enero-junio 2011, 41-74, ISSN: 0018-215-X 
Sobre el destino final de los manuales y textos hay dudas. Algunos indicios resultan poco alentadores al apuntar al poco aprecio hacia la cultura escrita. Desde Oropesa el 15 de octubre de 1783 escribe una carta al señor de la villa don Manuel de Huarte, capellán mayor y le indica que en la librería y cuarto del padre predicador «muchos libros se hallan muy ajados y carcomidos, los estantes maltratados y las ventanas hechas pedazos e inservibles» y pide al conde disponga que «se reparen con seguridad». Desde Madrid responden el día 24 del mismo mes. Se envía una misiva al administrador, don Francisco de Tapia y Herrera, reprochando su conducta y denunciando que esa situación «podías haber evitado si, en cumplimiento de tu obligación los hubieras hecho sacudir y ventilar de tiempo en tiempo; por si también han padecido en el número espero me le avises para confrontarle con el inventario de ellos que existe en mi archivo». ${ }^{21}$

Peor camino siguieron los libros del conde, según apuntan J. Ma . Gutiérrez y A. Moreno ${ }^{22}$ «en su biblioteca se conservaban gran cantidad de libros forrados en piel y hojas de pergamino, relativos a la historia señorial y condal de los Álvarez de Toledo y duques de Frías. Se cuenta que una parte de estos libros, cuando fue cerrada al culto en 1932, fueron tomados por algunos vecinos que lo utilizaron para hacer zambombas y prender la lumbre de sus hogares. La otra parte fueron cargados en dos vagones ferroviarios y conducidos al palacio de Montemayor en Córdoba, propiedad de los duques de Frías».

Los libros de otros colegios engrosaron o formaron ex novo bibliotecas que alcanzarían prestigio. En Granada la de los jesuitas, compuesta por 9.000 volúmenes, fue incorporada en 1786 a la Universidad, siendo su fondo más relevante. ${ }^{23}$ La de Soria, de calidad, pasó a la Universidad de Santa Catalina de Burgo

\footnotetext{
jesuitas de Murcia, Murcia, 2008), otras grandes estaban en Sevilla, Valencia, Tarragona, Oviedo o Valladolid; un grupo intermedio serían las compuestas entre 2.000 y 6.000 unidades en las ciudades populosas; para colegios en lugares más pequeños no descenderían de 1.000. Bernabé BARTOLOMÉ MARTínEZ, «Las librerías e imprentas de los jesuitas..., p. 352. En tierras americanas la biblioteca del colegio de san Luis de Potosí albergaba 813 títulos, equivalente a 1.909 volúmenes. José Luis BETRÁN MoYA, «Bibliotecas de Ultramar...», p. 310. En este trabajo aporta cifras de otros centros ubicados en Lima, México y Caracas, bastante superiores. Véase también Marcela INCH C, «La biblioteca potosina de la Compañía de Jesús», Historia y Cultura, 27 (2001), pp. 1-11; indica que el inventario se hizo en 1768 y comprende 2.189 obras en 4.413 volúmenes, repartidos entre la biblioteca común y los aposentos. Un pormenor de interés que aporta el artículo es la clasificación que los padres jesuitas adoptaron para su biblioteca: sin título, un grupo de obras religiosas; luego están los «Expositores», «Autores Societatis», «Canonistas y Legistas», «Historiadores Latinos», «Sermones» y «Tomistas Filósofos; sin título figuran algunas obras de literatura, bellas artes, historia, geografía y religión.

${ }^{21}$ A.H.N. Sección Nobleza. Frías C.1292, D. 1.

22 José Manuel GutiérRez RodrígueZ, Ángel Moreno Tejero y José Manuel Hernández Piña, Oropesa y los Álvarez de Toledo, Toledo, 1985, p. 42.

${ }^{23}$ Josefina Mateu Ibars, «La antigua librería del colegio de San Pablo en el siglo XVIII. Un principal fondo de la biblioteca de la Universidad de Granada», Cuadernos de Estudios Medievales y Ciencias y Técnicas Historiográficas 17 (1992), pp. 265-277. Sorprende el dato tan contradictorio sobre la
} 
de Osma. ${ }^{24}$ En Canarias, las de todos los colegios de la Compañía de Jesús se trasfirieron en depósito a la Biblioteca Pública del Seminario Conciliar, en 1767, y para su sostenimiento y actualización el rey Carlos III dedicó parte de las rentas de las diócesis vacantes. ${ }^{25}$ Hubo fondos bibliográficos incorporados a las bibliotecas de los palacios episcopales en un afán de darle un carácter de públicas y otros fueron a algún convento al que se le había entregado el edificio jesuita.

\section{TEMAS Y AUTORES DE LOS LIBROS}

Corporación docente de carácter religioso, en la Biblioteca del Colegio de san Bernardo de Oropesa, la mayoría de sus libros eran textos teológicos y filosóficos. Entra esto en contradicción con el modelo de «formación integral», auspiciada en la Ratio studiorum de la Compañía de Jesús. ${ }^{26}$

La preocupación por el estudio de la religión católica explica que los relacionados con la filosofía se concentren en la figura de Aristóteles ${ }^{27}$ y en Santo Tomás de Aquino. Otro problema para atender la temática es la abundancia de títulos de carácter genérico. Como Opera se recogen más de un centenar de libros. Había además misceláneas. Otras podrían adjudicarse a diferentes disciplinas, como las prolijas Vidas de..., a historia, a devocionarios, a órdenes religiosas... En otros casos el título da poca luz para identificar los asuntos que abordan.

riqueza patrimonial de la biblioteca que ofrece este autor 9.000 volúmenes, con el que aporta Inmaculada Arias que da 30.000. Inmaculada ARIAS DE SAAVEDRA, «Una biblioteca jesuítica de la Contrarreforma. Fondos de los siglos XV y XVI en el Colegio de San Pablo de Granada», en Enrique MARTínEZ RuIZ, Madrid, Felipe II y las ciudades de la Monarquía. Las ciudades: vida y cultura, Tomo III, Madrid, 2000, p. 209. De esta autora puede leerse también «La biblioteca de los jesuitas de Granada en el siglo XVIII», en Antonio Mestre SAnchis y Enrique GimÉnEz LóPEZ: Disidencias y exilios en la España moderna, Alicante, 1997, pp. 609-626.

${ }^{24}$ Bernabé Bartolomé MartíneZ, «Un centenario inadvertido: el colegio y estudio de los jesuitas de Soria (1576-1767)», Celtiberia, XXVI/52 (1976), pp. 207-220.

${ }_{25}$ Matías DíAz MARTín, «Libros prohibidos en la biblioteca del seminario conciliar de Canarias. Siglo XVIII», Parabiblos 3-4 (1989-1990) pp. 67-72. Había 3 colegios: La Laguna (300 volúmenes), La Orotava (746 vols.), Las Palmas (1.237 vols.). De esta última su composición era en cuatro categorías: jurisprudencia y cánones; predicación, espiritualidad, teología...; pedagogía gramática, clásicos y literatura castellana; matemáticas, idiomas y ciencias. En este trabajo se incluye una relación de libros prohibidos.

${ }^{26}$ Ramón SÁNChez GonZÁlez, La Compañía de Jesús... 29-34. Allí se cita abundante bibliografía sobre el ideario jesuítico.

${ }^{27}$ Conviene no olvidar que una de las enseñanzas que se impartían en el colegio eran los estudios de Artes cuyo objetivo fundamental era el conocimiento de la filosofía, a través del análisis de sus diferentes ramas, y el aprendizaje del pensamiento aristotélico.

Hispania Sacra, LXIII

127, enero-junio 2011, 41-74, ISSN: 0018-215-X 


\section{Religión}

Sobre las Sagradas Escrituras hay ocho registros con el título Biblia en distintos formatos y lugares de edición. ${ }^{28}$ Hay otros Nuevo Testamento con comentarios de Erasmo o de Arias Montano, y uno en griego, editado en Basilea en 1524. Se contabilizan 18 Viejo Testamento en hebreo, 12 en pasta y 6 en pergamino.

Sobre lengua hebraica, dos de Grammática, escritas por Alfonso Zamora y editada por Miguel Eguía ${ }^{29}$ en Alcalá, 1526 y Eduardo Slaugter (Roma, 1705), tres Tabulas in grammaticam hebream, de Nicolás Clenardo, editadas en París y Colonia en fechas distintas del Quinientos y un Alphabetum hebraicum que vio la luz en Amberes en 1569 de la mano de Cristóbal Plantino. ${ }^{30}$ Hay un Lexicon hebraicum compuesto por Elia Levita (Basilea, 1557), el Enchiridion sive Manuale hebraicum de Diego de Quadros, maestro de Sagrada Escritura y de Lengua hebrea en el colegio Imperial de Madrid, (Roma, 1733) y las tres Institutiones lingua hebraica de Roberto Belarmino impresas en Roma, Lyon y Colonia en 1585, 1596 y 1618 respectivamente.

Existe un complejo repertorio de Concordantia Bibliorum, Comentarii, Explicatio, Expositio sobre capítulos concretos como los profetas, los ángeles, el Pentateuco, los evangelistas, el Apocalipsis, los salmos..., ${ }^{31}$ compuestos por miembros de numerosas órdenes religiosas tales Avendaño, Oleastro (O.P.) Alapide, Baeza, Barradas, Pineda (S.I.), Orozco (O.E.A) o Paes (O.T.). Hay también una decena de Evangelia escritos por Cayetano Fero, Escobar de Mendoza y García del Valle y algún estudio comparativo como la Analogía veteris ac novi testamenti de Martín Becano y casi otros tantos dedicados a reflexionar sobre las Epístolas del apóstol San Pablo, firmadas por Juan Antonio Velázquez, Tomás de Vio Cayetano, Francisco de Ribera, Baltasar Paes y Domingo de Soto.

El término «Teología moral» es un lugar común a la hora de identificar el contenido de los libros. Acompañado de calificativos como Selecta, Summa, Tractatus Resolutiones (13 volúmenes de a folio escritos por Antonio Diana Panormitani) o Sententiam proliferan a lo largo del inventario.

\footnotetext{
28 Una en seis tomos de folio está publicada en Lyon 1590.

${ }^{29}$ Sobre el papel de Miguel de Eguía y la Officina Typographica Complutense véase Jacobo SANZ HERMIDA, «La imprenta y la difusión de la espiritualidad erasmista», en Erasmo en España. La recepción del humanismo en el primer Renacimiento español, Salamanca, Sociedad Estatal para la Acción Cultural Exterior, 2002, pp. 129-139

${ }^{30}$ Para conocer la personalidad de este impresor y su importancia en el mercado editorial puede leerse Colin Clear, Cristóbal Plantino. Editor del Humanismo, Madrid, Rialp, 1964 o el más antiguo de Max Rooses, Christophe Plantin imprimeur anversois, Amberes, 1896. Sobre la influencia y el apoyo que le concedió el cardenal Granvela es útil el libro Maurice Van Durme, El cardenal Gravela (15171586), Barcelona, 1955. Edición facsímil por la FEHM, Madrid, 2000, pp. 298-301.

${ }^{31}$ Con el título Canticum canticorum salomonis hay obras de los frailes Luis de León, Luis Sotomayor y del jesuita Martín del Río en las que se dan explicaciones e interpretaciones sobre su contenido.
} 
Apartado muy sobresaliente es el de los grandes pensadores de la Iglesia con Tomás de Aquino a la cabeza. Hay medio centenar de libros de su Summa Theologica, y de Commentaria a diferentes obras de Aristóteles, editados en la segunda mitad del siglo XVI y procedentes de estampaciones en Alcalá, Augusta, Venecia, Lyon, Padua, París y Roma. Por si fuera poco existen heterogéneos estudios dedicados a escudriñar su pensamiento compuestos por Albelda, Albertino, Alberto, Becano, Jacobi Castro, Cayetano, Conink, Cumel, Curiel, Fasolio, Ferrara, Herice, Agustín de Herrera, Pedro Hurtado, 32 Joverio, Lorca, Luis Molina, Prepósito, Ragusa, Salas, Francisco Suárez ${ }^{33}$-tiene diez registros de Commentarii ac disputationum... Divi Thoma editados en diferentes sitios-, Luis Turriano, Vatablo, Gabriel Vázquez, jesuita español y uno de los máximos conocedores de la doctrina tomista -18 registros Commentariorum ac disputationum... S.Thoma publicados en Alcalá de Henares entre 1598 y 1621 por Joannis Gratiani. ${ }^{34}$ Todo ello nos lleva a afirmar que la figura de Tomás de Aquino y su filosofía se convierte en el eje fundamental sobre el que se estructura la biblioteca jesuítica del colegio oropesano y que nos recuerda el peso destacado del pensamiento escolástico durante toda la Edad Moderna

Otros teólogos, muchos de los cuales alcanzaron la gloria de los altares, con abundancia de títulos son Agustín, Ambrosio, Antonio, Atanasio, Basilio, Bernardo, Cipriano, Cirilo, Epifanio, Jerónimo, Gregorio, León y Pagnino, de la mayoría de los cuales se citan sus obras completas bajo la habitual y genérica denominación de Opera u Opera Omnia.

También de carácter general tanto para la teología como para la filosofía, dos disciplinas tan imbricadas una en la otra que con frecuencia se solapan e incluso se confunden, son los Compendios, las Controversias -las hay contra los calvinistas, husitas, witclevistas-, Disputationes, Questiones. Todavía más amplio son los Discursos espirituales (Croiset), morales (Azevedo, Náxera, Porres) o tan curiosos como si se puede hacer fiesta a Adán o sobre la tradición de

32 Un ilustrativo análisis de la estampa realizada por el grabador Juan Courbes en el libro de Hurtado Scholasticae et Morales Disputationes...(Salamanca, 1631) en Rosa M. CACHEDA BARREIRo, «Imagen y reflejo. Autoridad cristiana y poder religioso a través de los modos iconográficos», en El culto a los santos: cofradías, devoción, fiestas y arte, San Lorenzo de El Escorial, Ediciones Escurialenses, 2008, pp. 469-470.

${ }^{33}$ Leopoldo PRIETO, «Vida y pensamiento del padre Francisco Suárez», Ecclesia XX, 2 (2006), pp. 187-210. Un reciente trabajo sobre este personaje puede leerse en Ramón KURI CAMACHO, «Francisco Suárez, teólogo y filósofo de la imaginación y la libertad», Revista de Filosofía 58 (2008-I), pp. 79101.

${ }^{34}$ La obra citada de Vázquez es una de las de mayor precio de las existentes en el colegio jesuita granadino de san Pablo. Inmaculada ARIAS DE SAAVEDRA, «Los libros privados de los profesores del colegio jesuita de san Pablo de Granada. Siglo XVIII», en Aulas y Saberes. VI Congreso Internacional de Historia de las Universidades, Valencia, Universidad de Valencia, 2003, vol. 1, pp. 159-179. Gabriel Vázquez, definido por Benedicto XIV como «antorcha de la Iglesia» escribió sobre san Pablo y los Padres de la Iglesia y expuso la doctrina moral.

Hispania Sacra, LXIII

127, enero-junio 2011, 41-74, ISSN: 0018-215-X 
la venida del apóstol Santiago a España. En el campo de la filosofía son frecuente los Cursus philosophicus escritos por Arriaga, García de Vera, Lalemandet, Losada, Polanco y Peñafiel, los Institutiones sobre filosofía y dialéctica redactados por Pedro Fonseca, Francisco Alfonso Malpartida y Gaspar Sagner o los Universa philosophia de Pedro Hurtado de Mendoza y de Ricardo Linceo.

Sesudos estudios de teología están dedicados a los sacramentos, a Dios, a Jesucristo, al alma, a la predestinación, a la encarnación, la mayor parte agrupados bajo la denominación de Tractatus. Singular valor se aprecia en los que abordan la figura de la Virgen María y de forma particular su Inmaculada Concepción, a pesar de que hasta 1854 no será declarado dogma por la Iglesia. ${ }^{35}$

Un contingente sustancial de libros esta formado por una extensa serie de obras de gran utilidad para los sacerdotes en el desempeño de sus funciones pastorales. En este contexto habría que situar la amplia gama de dos conjuntos bibliográficos, lo que podríamos denominar «Manuales» y los sermones, predicaciones, homilías. Respecto a los primeros son muy conocidos títulos como Avisos de curas de Bernal, Instrucción de sacerdotes de Francisco Toledo o con idéntico nombre el que escribió Antonio de Molina, Manual de confesores y penitentes de Azpilcueta, ${ }^{36}$ abundando en esta última temática cabe mencionar Casos de conciencia de Sayro, Sumas de casos de conciencia de Juan de Pedraza y otro del franciscano Manuel Rodríguez, ${ }^{37}$ Manual místico para confesores de Pedro Zapata Coronel, Promptuario de Teología moral de Francisco Lárraga, ${ }^{38}$ que en 1747 había alcanzado su 29 impresión. Más genéricos son El cura instruido de Pablo Señeri, El perfecto religioso de Francisco Aguado, Bien del estado religioso de Francisco Rodríguez.

${ }^{35}$ Los autores que dedican libros, existentes en la librería colegial, a esta cuestión son Francisco Quirino de Salazar, Pedro de Ojeda, Jacob Granado, Juan de Luca, Antonio Gutiérrez de la Sal, Juan Bautista Lezana, Jerónimo de Andrada y Juan Antonio Velázquez. El fervor concepcionista estuvo muy arraigado entre los teólogos de finales del siglo XVI y primera mitad del XVII. Santiago SEBASTIÁN LóPEZ, Contrarreforma y Barroco, Madrid, Alianza Editorial, 1989, p. 278.

36 «contiene cuasi todas las dudas que en las confesiones suelen ocurrir de los pecados, absoluciones, restituciones, censuras e irregularidades. Con cinco comentarios de usuras, cambios, simonía mental, defensión del próximo, de hurto notable e irregularidades».

37 «con advertencias muy provechosas para confesores, con un orden judicial a la postre, en la cual se resuelve lo más ordinario de todas las materias morales. Añadida ahora de nuevo en muchas cosas y corregida por el mismo autor. Con licencia del Supremo Consejo de S.M.. Al fin va un índice copioso de las cosas notables, nuevamente hecho por el mismo autor; y otro índice de todos los lugares del concilio tridentino que se declaran en estos tratados».

38 «muy útil para todos los que se han de exponer de confesores y para la debida administración del Santísimo Sacramento de la Penitencia, nuevamente reconocido, mejorado, corregido y añadido por su autor en esta décima octava impresión». 
Centrados en la liturgia cuentan con Ceremonial rezado de la misa de Olalla y otros varios sobre preces, letanías, ritos y cultos. Los sermonarios cubren toda una gama de opciones y posibilidades en función del calendario litúrgico. Con la denominación Sermones hallamos 58 registros de autores muy diferentes ${ }^{39}$ y en idiomas también diversos, latín, castellano, portugués. Homilía y Homiliarum son otro grupo nutrido, algunos como los de Juan Eckil en cuatro volúmenes (París, 1549); muy útil fue Silva espiritual de Antonio Álvarez ${ }^{40}$ y Conocimiento de si mismo de Antonio Navarro. ${ }^{41}$

Las hay para los domingos (Niseno), ajustados en la Cuaresma (Barcia, Burdalue), dirigidos a misioneros, para los entierros Cien oraciones fúnebres de Luis de Rebolledo... incluso hay dos Bibliotheca homiliarum et sermonum. Se verifica la recopilación de sermones predicaciones en lugares muy concretos, ya fueran en la Corte, en templos metropolitanos o en algún hospital.

Lo que podríamos calificar como devocionarios están muy presentes. Aquí se incluirían los abundantes textos de espiritualidad, de exaltación de las virtudes cristianas, de moralidad, rezos y oraciones... Podemos citar los celebrados Ejercicios espirituales desde el clásico del fundador de la orden Ignacio de Loyola hasta los no menos clásicos por su extraordinaria divulgación y sus numerosas ediciones escritos por Antonio Molina o Pedro de Valderrama ${ }^{42}$ o el Manual de Ejercicios espirituales de Villacastín.

Otros títulos consagrados eran la Imitación de Cristo, sobre todo el de Tomás de Kempis, si bien hay otro igual, redactado por Francisco Arias, o De los nombres

${ }^{39}$ Los escritos por el carmelita descalzo Diego del Espíritu Santo «contiene una tabla de los sermones y un índice de las cosas más notables y otro de los lugares de la Sagrada Escritura más especiales que se explican, con estilo particular para su más pronta inteligencia y aplicación.

40 Predicador de la orden franciscana en su convento de Salamanca. El libro se repite en tres ocasiones, en una se aclara que es la $2^{\text {a }}$ edición corregida de 1589 , dirigida a doña Mencía de Requesens y Zúñiga, condesa de Benavente, en otra se detalla que se trata de la $4^{\mathrm{a}}$ impresión de Salamanca («sin las demás peregrinas de otros reinos») y la fecha 1594. En ella se añade una tabla alfabética de materias, útil para los predicadores. El libro contiene «consideraciones para el entretenimiento del alma cristiana» sobre los seis domingos de Cuaresma, día de la Anunciación, conversión de la Magdalena... El último registro citado es la edición en Salamanca 1603, ahora con Artus Taberniel. En 1595 aparece unas Adicciones de la silva espiritual.

41 «utilísimo tratado para todo género de estados especialmente para predicadores por haber en él varios lugares de la Sagrada Escritura; testimonios de doctores santos y de graves autores y sentencias de filósofos antiguos, poetas, historiadores y textos del derecho canónico y civil. Tiene muchas tablas, y en particular de consideraciones para los sermones que en el año más comúnmente se predican».

42 Agustino, natural de Sevilla. Sus Ejercicios espirituales para todos los días de la Cuaresma en tres tomos están dedicados cada uno a diferentes personalidades. Fernando Niño de Guevara, cardenal arzobispo de Sevilla y del Consejo de S.M.; Juan Niño de Guevara, conde de Añover de Tormes, del Consejo de S.M.; Francisca Enríquez de Fajardo, marquesa de Alcalá y Chucena, señora del mayorazgo de Baca.

Hispania Sacra, LXIII

127, enero-junio 2011, 41-74, ISSN: 0018-215-X 
de Cristo de fray Luis de León (Salamanca, 1585). De gran éxito y presentes en la biblioteca los Flos sanctorum de Alonso de Villegas, ${ }^{43}$ Martín de Roa, ${ }^{44}$ Pedro Ribadeneyra y Francisco García. A estos, por su similitud, podríamos incorporar los Martirologios de Baronio o de Galesionio. Un capítulo aparte merecen los Catecismos -13 en total- de Jerónimo Ripalda, Manuel Rodríguez, ${ }^{45}$ Edmundo Augerio y Pedro de Lepe, ${ }^{46}$ más las Prácticas del catecismo romano y doctrina cristiana de Nieremberg ${ }^{47}$ o la conocida Luz de verdades católicas y explicación de la Doctrina cristiana, ${ }^{48}$ de Juan Martínez de la Parra, con once estampaciones.

Con la inclusión del término «espiritual» en el título descubrimos varias composiciones, unas genéricas como las Obras espirituales de Luis de la Puente o Juan de la Cruz, ${ }^{49}$ otras más concretas Aprovechamiento espiritual de Francisco Arias, Camino espiritual de Palma, una ampliación de los Ejercicios de san Ignacio. Existen numerosas Oraciones orientadas al rezo mental, a periodos específicos del calendario cristiano (Adviento, Cuaresma) o a devociones personales como Jesucristo o la Virgen María.

Debe añadirse el Diálogo sobre la necesidad de la oración del dominico Juan de la Cruz. Heterogéneas son las Meditaciones de Cuaresma, sobre los misterios de la fe o sobre santos. Con títulos más sutiles figuran obras del estilo

43 Sacerdote teólogo y predicador, capellán en la capilla iglesia de Toledo y beneficiado de san Marcos, natural de Toledo. Flos sanctorum más «discursos y sermones sobre los evangelios de las dominicas del año, ferias de Cuaresma y de santos principales. Se contienen exposiciones literales, doctrinas morales, documentos espirituales, avisos y ejemplares provechosos para todos estados».

44 «fiestas y santos naturales de la ciudad de Córdoba, algunos de Sevilla, Toledo, Granada, Jerez, Écija, Guadix y otras ciudades y lugares de... Castilla y Portugal; con la vida de doña Sancha Carrillo y la de doña Ana Ponce de León, condesa de Feria, revisada y acrecentada».

45 «Muy provechoso no solamente para predicadores, confesores, rectores y curas, mas aun para cualquier cristiano, pues en él se declaran con espíritu llano y devoto los principales misterios de nuestra Fe».

46 «contiene la explicación de los principales misterios de nuestra santa fe católica y las demás cosas que debe el cristiano saber para su salvación».

47 «sacada principalmente de los catecismos de Pío V y Clemente VIII. Compuestos conforme al decreto del Concilio de Trento... para que se pueda leer cada domingo y día de fiesta». Juan Eusebio Nieremberg es uno de los escritores más reputados en el seno de la Compañía con la particularidad de que todas las obras contenidas en la biblioteca de Oropesa -16 registros- están escritas en español. Probablemente su trabajo más divulgado fue el citado catecismo junto a otros dedicados a glosar y ensalzar la figura del fundador y de otros padres jesuitas. Todas sus publicaciones fueron impresas en Madrid, la mayoría por María Quiñones, en los años centrales del Seiscientos.

48 «que siguiendo la costumbre de la Casa Profesa de la Compañía de Jesús de México, todos los jueves del año ha explicado en su iglesia [el autor]». Contiene tres tratados: explicación de la Doctrina cristiana, decálogo de los mandamientos, y sacramentos. Se indica que el cardenal Carlos de Borja concede indulgencias a quienes leyeren u oyeren leer este libro.

49 «que encaminan a una alma a la perfecta unión con Dios». Contiene una «resunta de la vida del autor y unos discursos por el P. Fray Diego de Jesús, Carmelita Descalzo Prior del Convento de Toledo... En la portada no consta el año de su edición y el privilegio real se despachó en Aranjuez a cinco días del mes de mayo de mil seiscientos y diez y ocho». 
de Ejercicios de perfección y virtudes cristianas de Alonso Rodríguez, Luz del alma cristiana compuesta por Felipe de Meneses con dos ediciones, una en Sevilla (1555) y otra en Medina del Campo (1567).

En cierto modo relacionados con los devocionarios, por lo que tienen de conductas ejemplarizantes son el nutrido grupo de Vidas. Podrían catalogarse como biografías o como libros de historia en la medida que al estudiar a un personaje recogen una época y un contexto social. En realidad su presencia obedece más al matiz de composición edificante para la conducta religiosa del lector más que para ampliar sus conocimientos históricos, aunque siempre despertaría la curiosidad.

Son jesuitas los principales protagonistas de las crónicas biográficas, escritas asimismo por miembros de la orden Ad maiorem gloriam si bien más que de Dei de la Societati Iesu. Del fundador son sobradamente conocidas las de Nieremberg, Ribadeneyra o Francisco García. Francisco Javier, apóstol de las Indias fue objeto de estudios escritos por Lucena, García, Peralta y Trigault. Otros biografiados son Carlos Borromeo (Muñoz), Francisco de Borja (Cienfuegos), Luis Gonzaga (Virgilio Cepari, traducida del italiano por Juan de Acosta). Hay además una larga nómina de jesuitas no todos muy conocidos ni relevantes en un contexto general pero sí interesantes para el uso doméstico dentro de la institución. ${ }^{50}$ Se hallan también Varones ilustres de la Compañía de Jesús (Madrid, 1729) o Glorias del segundo siglo de la Compañía de Jesús escrito por el jesuita, miembro de la Real Academia Española, José Cassani en seis tomos de a folio (Madrid, 1734).

El resto del fondo biográfico, muchos menos numeroso, gira alrededor del santoral cristiano, desde el genérico De vitis sanctorum, escrito por Aloisio Lippomano (Amberes, 1586), que perfectamente podríamos haber incluido entre los Flos sanctorum, hasta monográficos dedicados a santa Lutgarda, santa Ángela de Fulgino o a otros más conocidos como Teresa de Jesús, san Francisco, san Julián o santo Domingo. Completa la categoría una obra sobre doña Catalina de Mendoza y otras consagradas a glosar la trayectoria vital de Tomás de Villanueva, el maestro Juan de Ávila o Estanislao Kostka.

50 Entre otros se citan a Francisco Jerónimo (Frías), Francisco Suárez (Sartalo), Jerónimo Dutari (Lardizábal), Luis de Medina (García), Ignacio de Azevedo, Francisco Díaz del Ribero (Aranda), Baltasar Álvarez (Puente), José de Ancheta (Paternina), Francisco Aguado (Andrade) y Alonso Rodríguez (Colín).

Hispania Sacra, LXIII

127, enero-junio 2011, 41-74, ISSN: 0018-215-X 


\section{Clásicos}

El mundo de los clásicos, mucho más el romano que el griego, constituyó durante centurias el faro de referencia que iluminaba la enseñanza tanto la universitaria como la de los colegios de latinidad. Representaba la mirada hacia donde convergían los intereses de cualquiera de las disciplinas objeto de estudio.

Habría que empezar por recordar que el aprendizaje del latín y del griego formaba parte de las materias de estudio, especialmente el primero, pues en los centros de la Compañía estaban obligados a hablar siempre en latín, tanto en las actividades académicas como en el tiempo de ocio. Eso explica la presencia de numerosas Gramáticas ${ }^{51}$ griegas, diccionarios ${ }^{52}$ u obras como Arte para aprender la lengua griega, Institutionum lingua greca de Jacobi Gretsero o la de Nicolás Clenardo, Enchiridion greca lingua de Palmyreno o la editada en París en 1755 Introductionum a lingua grecam. Aparecen otras relacionadas con la enseñanza-aprendizaje del latín como las Advertencias de modos y tiempos «para formar estilo elegante latino» de Baltasar Henríquez, jesuita irlandés, teólogo salmanticense y profesor de elocuencia en el Seminario de la Compañía de la Provincia de Toledo, o el texto de Tomás García de Olarte Observaciones selectas de los modos de oraciones latinas, «conforme se enseñan en los estudios de la Compañía de Jesús» con un apéndice al final.

Entre los autores de la Hélade descubrimos a Homero y sus Iliada y Odisea con ediciones del XVI y del XVIII en París, Basilea y Ámsterdam; Jenofonte Operum/ de rebus grecorum Basilea, en griego en 4 vols.; Diógenes, Platón con estudios de Marsilio Ficino y por encima de todos irrumpe la figura incuestionable de Aristóteles, al que no dudamos en calificar como el gran icono intelectual de la época junto a Tomás de Aquino. Del gran filósofo, educador de Alejandro Magno, se recogen todas sus obras en 40 tomos -Ética, Física, Lógi-

${ }^{51}$ La más antigua es la de Miguel Humelbergio (Basilea 1532) y la más próxima la Compendiaria grece grammatices (Padua 1756). Entre medias hay otras del XVI de Jacobo Ramírez, Constantino, Lascaro, Juan Nunesio o la de Francisco Vergara.

52 Con diferentes títulos y ediciones diversas en cuanto a fecha y lugar de publicación encontramos los conocidos de Ambrosio Calepino y Elio Antonio Nebrija así como Compendio latino hispano o Calepino de Pedro de Salas, autor igualmente del Vocabulario latino-español, el Lexicom grecolatino de Juan Hartongo y el de Cornelio Schrevelio o el voluminoso en 4 tomos de folio Distionarum seu latina lingua thesaurus impreso en París en 1543 por Roberti Stephani del que se anota que es la edición 21. Conviene recordar la tradición existente de este tipo de obras con anterioridad a la invención de la imprenta. Se trata de manuscritos compuestos para auxiliar no sólo en el conocimiento de una lengua sino también para ayudar a predicadores, juristas o para entender mejor textos concretos como la Biblia. Rudolph HIRSCH, «Imprenta y lectura entre 1450 y 1550», en Armando PETRUCCI, Libros, editores y público en la Europa moderna, Valencia, Edicions Alfons el Magnanim,1990, pp. 44-45. 
ca, Metafísica, Dialéctica, Omnia opera, Arte rethorica, De celo,... editadas en Lyon, Venecia, Basilea, Génova y París, a lo largo de la segunda mitad del Quinientos.

Mucho más significativo a la hora de realzar su influencia en el pensamiento de la época es constatar la existencia de decenas de textos dedicados a escrutar su filosofía redactados bajo las formulas genéricas de Commentari por autores como Francisco Toledo, más de veinte libros publicados en Alcalá de Henares durante la década de 1580, Pedro Fonseca, cuyos escritos vieron la luz en ciudades como Colonia, Coimbra, Lyon o Roma o el prolífico Antonio Rubio, doctor en Teología y profesor de la Complutense que supera la treintena de tomos; Disputationes como las de Ignacio Francisco Peinado, ${ }^{53}$ editadas en la misma ciudad entre 1667-1698; Selecta tales la de Francisco Murcia de la Llana impresas en Madrid por Luis Sánchez y la Tipografía regia a principios del Seiscientos.

Aparte de los mencionados se contabilizan otros 38 escritores $^{54}$ que de forma exclusiva o dentro de una producción más amplia con conexiones más o menos próximas al pensamiento aristotélico, abordan la personalidad del Estagirita. .5

Más fecunda es la huella literaria de la cultura romana y mucho más nutrido el catálogo de escritores. La filosofía se encuentra en la cima alzándose como una de las ciencias que mayor pasión despiertan, en particular las obras de Cicerón y de Séneca. Aquí el máximo protagonismo corresponde a Marco Tulio Cicerón y a sus conocidos estudios Epistolarum -con una edición en Amberes de 1517- De oficiis -la más reciente, Madrid, 1664)-Rethoricorum, Opera philosophica con publicaciones repartidas por Basilea, Lyon o París. Corolario inexcusable la plétora de escritores que dedican su tiempo a indagar sobre su pensamiento, entre los que cabría citar al maestro, profesor de letras humanas y filosofía en la universidad de Zaragoza, Pedro Simón Abril, Epístolas selectas de Cicerón, «en que se pone el uso de Cartas narratorias y de favor llamadas

\footnotetext{
${ }^{53}$ Miembro de la Compañía como los anteriores, calificador de la Inquisición, examinador sinodal de la diócesis toledana, catedrático de Teología de la universidad Complutense y confesor de la reina Maria Ana

${ }^{54}$ Alexandri Afrodiseo, Alexandri de Ales, Aquino, Juan Argyropylo, Cardillo, Celaya, Climent, Colegios Complutense y Conimbricense, Gaza, Guastavinio, Crisóstomo Javelo, Diego de Jesús, Andrés Laguna, Lemosio, Pedro Martínez, Massio, Mureto, Natal de Comitibus, Agustín Nipho, Pedro de Oña, Palomeque, Perionio, Plaza, Porphirio, Rocha, Rota, Ruiz, Juan Sánchez, Pedro Serrano, Severino, Simonio, Simplicio, Domingo de Soto, Cipriano Suárez, Titelmano, Francisco Valles y Vatablo.

${ }^{55} \mathrm{Me}$ refiero a personalidades como la de Gaspar Carrillo Villalpando, teólogo segoviano, doctor y profesor de Artes en el colegio de san Ildefonso de la Complutense autor de las conocidas Súmulas citadas en el Quijote de Miguel de Cervantes. En la biblioteca de Oropesa constan tres ediciones distintas de las Summa Summularum de 1570, 1577 y 1586 todas ellas en Alcalá de Henares aunque de prensas distintas, las de Joannis Gratiani y Joannis Iñigues de Lequerica
} 
comendaticias puestas con traducción y declaraciones en lengua castellana», según reza el inventario o a Aldo Manucio. ${ }^{56}$ Del cordobés Lucio Anneo Séneca figuran cinco ejemplares de sus Tragedias -la primera edición en París, 1514y reiteradas disertaciones, comentarios vinculados al estoicismo, como los de Curión, Martín del Río, Marco Antonio Mureto, o relacionados con otras disciplinas, tal sucede con Alonso Núñez de Castro ${ }^{57}$ o el mismo Erasmo de Roterdam, del que nos ocuparemos más adelante. La historia es otro género donde se prodigan autores como Julio César, Tito Livio Historia principes decades (Basilea, 1539), Salustio cuatro ejemplares distintos de Conjuratio Catilinae et bellum Iugurtinum, Flavio Josefo y su conocida Antiquitatum judaicarum, Lucano De bello civile, Floro Gestorum romanorum, Epítomes, Tácito Annalium, Plinio Historia mundi (dos ediciones Basilea 1539 y Lyon 1548).

De entre los clásicos de la literatura constan Horacio, Ovidio Metamorfosis, Virgilio, Juvenal con sus Sátiras, Marcial y los Epigramas, Plauto Comedia, (Alcalá, 1518), Plutarco, Quintiliano, Terencio, Tertuliano, Luciano, Orígenes, Valerio, Vitrubio y Pomponio Mela con su De situ orbis, (Lyon, 1538). Se constatan, por otro lado, libros que investigan otros personajes relevantes de la cultura clásica aunque no disponen de textos originales, como sucede con Esopo o Demóstenes. ${ }^{58}$ Aparcamos momentáneamente las referencias, reiteradas, a los clásicos de la medicina que abordaremos en otro apartado.

En clara conexión con el ámbito grecorromano hay que situar a los humanistas de la época del Renacimiento -clásicos desde otro punto de vista- de la que existe una muestra significativa, hasta en algunos casos, sorprendente como ocurre con Erasmo cuyas relaciones con las órdenes religiosas no fueron precisamente idílicas, sino todo lo contrario, estando esa oposición en la base de la persecución y condena que en la época de Felipe II sufrirían el erasmismo y sus seguidores. De Erasmo de Rótterdam se citan una decena de registros ${ }^{59}$

56 Se citan a Boulieiro, Camerario, Pedro Lagnerio, Mario Nizolio, Juan Nunesio Valentino y Cipriano Suárez.

57 De forma inusual aparece en castellano Séneca impugnado en cuestiones políticas y morales, (Madrid, 1661, 2 impresión) editada por Pablo de Val.

58 Reflexiones y comentarios sobre los autores están los textos de Ciófano, Constantino (Ovidio); Cruserio, Xilandro (Plutarco); Fabricio, Lambino (Horacio); Orio, Pamelio (Tertuliano); Rhenano, Sueyro (Tácito); Gelenio (Flavio Josefo), Juvencio (Terencio), Micyllo (Luciano), Olivario (Mela), Planude (Esopo), Suárez, (Quintiliano), Wolfio (Demóstenes).

${ }^{59}$ Con un abanico de publicación situado entre Maguncia 1521 el más antiguo y París 1563 . Hay ediciones de Alcalá por Miguel de Eguía, 1529 -no se especifica el título- de Colonia y de Lyon. Complementario es la obra de Juan Frobenio sobre el Nuevo Testamento de Erasmo, Basilea, 1527. A veces bajo un mismo registro se ocultan varias obras como sucede con Dulce bellum in expertis que comprende además Adversus februcitantis, (Basilea, 1529); Apología monástica religionis, (Salamanca, 1528) del erasmista Ludovico Carvajaldo, dedicada al marqués de Priego; Antibarbarorum, (Argentorati, 1527, Joannem Knoblocum). 
cuyo contenido varía entre comentarios de Séneca y Flavio Josefo, las Sagradas Escrituras o su conocida Apopthegmatum. Del italiano Lorenzo Valla Elegantiarum latina lingua (Lyon, 1548, Sebastianum Griphium) y De lengua latina; entre los españoles cabe citar a Juan Luis Vives Dialogistica lingua latina exercitatio, Antonio Nebrija, Benito Arias Montano o la decena de obras sobre teología y filosofía de Alfonso de Madrigal El Tostado editadas en Venecia, alguna como Opera preclarissima en fecha tan temprana como 1507 en los talleres de Gregorium de Gregoriis; el resto entre 1528 y 1530 la mayoría impresas por Petri Liechtenstein. Hay alguna más de Rodolfo Agrícola y de Marsilio Ficino.

Si bien los datos aportados por el inventario analizado no permiten extraer conclusiones rigurosas, si podemos intuir que la existencia de humanistas tan selectos como los citados refleja una penetración del humanismo en medios escolares eclesiásticos, con lo cual se abre una puerta para indagar sobre su importancia, si afecta en exclusiva a la Compañía de Jesús o si se puede generalizar a otros centros de enseñanza.

\section{Medicina}

Un aspecto que llama poderosamente la atención al analizar el contenido del patrimonio bibliográfico del colegio de san Bernardo de Oropesa es la presencia tan sustancial de libros de Medicina. ¿Cómo explicar esta circunstancia? Aunque sólo sea a modo de hipótesis, sin que hallemos un fundamento sólido que justifique una explicación, nos atrevemos a lanzar varios interrogantes. ¿Puede tener alguna relación con la existencia en la villa del hospital de san Juan Bautista para pobres enfermos, erigido, como el colegio, por la munificencia del virrey de Perú y puesto bajo la tutela de la Compañía de Jesús? ¿Servían sus textos de apoyo científico para los médicos y cirujanos que lo atendían? ¿Obedece a la afición por esa disciplina de alguno de los padres encargados de la adquisición de los libros? Aunque ignoremos la razón que nos ayude a desentrañar este enigma, se computan nada menos que 65 autores que rondan el centenar de volúmenes.

La temática específica que aborda es muy variada. Proliferan los comentarios y anotaciones de los dos médicos clásicos por excelencia de la antigüedad, Hipócrates y Galeno. ${ }^{60}$ Los estudian de manera conjunta Luis Collado, Juan

${ }^{60}$ De Claudio Galeno se computan 5 registros (11 vols.) Las obras citadas son Opera, Omnium opera, De ossibus ad tyrones, De antidioti publicadas entre 1551 y 1586 en Lyon y Venecia. La Omnium opera son cuatro libros que contienen diferentes obras con los siguientes títulos: Omnium operum, (Venecia, Vincentium Valgrisium, 1562), Galeni librorum «se halla escrito todo en griego» (Basilea, 1538), In libros Hippocratis et aliorum comentarii, (Venecia, Vincentium Valgrisium, 1562).

Hispania Sacra, LXIII

127, enero-junio 2011, 41-74, ISSN: 0018-215-X 
Cornario dedica seis tomos, Juan Bautista Montano, Antonio Musa Brasavoli con textos publicados en Venecia, Lyon y Basilea, Nicolás Rorario, Ugo, Juan Vaseo y Cristóbal Vega.

Los Aforismos hipocráticos son examinados por Plantío y la figura de Galeno es indagada en su conjunto por Martín Acakia, Nicolás Leoniceno, Tomás Linacro, Juan Bautista Montani Lublino, Fernando Mena, Trincavelio, Tomás Rodrigo de Veiga; de forma más limitada por Tomás Garbo; Héctor Gibalto se centra en su discurso sobre la fiebre y Teodorico Gaudano estudia los medicamentos.

A estos padres de la medicina habría que incorporar otro par de tratados de excepcional relevancia como son el Dioscórides de Andrés Laguna, el Humani corporis fabrica de Andrés Vesalio (Lyonuni, 1552) y más aún de Avicena, Medicinis impresa en Venecia, 1492 por Baptista de Tortis en cuatro tomos de folio y marca, traducida del árabe al latín por G. Cremonense y que constituye una de las joyas bibliográficas de la librería jesuita de Oropesa. Insistiendo en la medicina musulmana hay un libro de Jerónimo Doncellini y otro de Andrea Alpago, experto en árabe traductor al latín de Avicena.

Aparecen obras de conjunto sobre la ciencia médica del estilo de Summa medicinalis de Tomás de Barbo, Práctica médica de Juan Bauman, De re medica escrita por Aurelio Celso y otra de igual enunciado de Juan Mesia, De medici compuesta por Leonardo Botali, Practica medicinali de Leonello Faventino.

Otras fijan su atención es aspectos más específicos como las pestilencias, un fenómeno frecuente en la época y que causaba estragos entre la población, de la que se ocupan Nicolás Bocangelino, Lorenzo Jouberto, Luis de Mercado, médico de Felipe II que dedica cuatro libros a estudiar las pestes, la fiebre y las instituciones médicas, Julio Palmario Constantino; de las afecciones infantiles escribió Francisco Pérez Cascales deán de la catedral de Sigüenza y profesor de medicina en su universidad, sobre mortalidad femenina Miguel Columbo, A1fonso Lupeyo elaboró un estudio sobre el tabardillo publicado en Zaragoza en 1574, Pedro Victoria redactó una investigación sobre la epilepsia publicada en Sevilla 1610; de medicamentos, hierbas para purgar, plantas medicinales cuentan con ensayos de Juan Bravo doctor en la universidad de Salamanca, Remberto Dodoneo, Juan Fernelio, Gorreo, Jacobi Hollerie Stempani, Pedro Pablo Pereda, Guillermo Rondelicio, Pedro Vaecio.

No faltan composiciones que se sumergen en controversias y disputas médicas como las de Pedro García Carrero, Juan Manardo, en comentarios de anatomía (Matías Curcio), la ciencia médica en su globalidad, la medicina práctica (Velasco de Tharanta), misceláneas del estilo de Juan de Vigo, autor de una Opera en la que se compilan tratados de cirugía, anatomía, estudios sobre úlceras, de morbo gallico, fracturas y dislocaciones, antídotos composición... o en algo tan solemne como Retrato del perfecto médico 
compuesto por Henrico Enriquez ${ }^{61}$ dedicado al duque de Alba y publicado en Salamanca el año 1596.

Por último merece la pena resaltar la proliferación de obras de Francisco Valles, covarrubiano, profesor en la Complutense y protomédico del rey Felipe II. Hay una docena de registros en los que, amén de abordar la filosofía de Aristóteles, dedica la mayoría del contenido a la medicina con comentarios a obras de Galeno e Hipócrates junto a títulos destinados a controversias médicas y filosóficas, métodos curativos o un pasaje sobre la orina, el pulso y la fiebre. Los libros fueron editados en Alcalá (Andrea de Angulo) Augusta y Lyon entre 1561 y 1595.

\section{Historia}

Alrededor de una treintena de libros corresponden a historia, un porcentaje exiguo en el conjunto del patrimonio bibliográfico del colegio de san Bernardo, siendo la mayoría de temas eclesiásticos o de la Compañía de Jesús.

Las más conocidas de todas son las obras de Enrique Flórez Clave Historial / España Sagrada (19 vols. Madrid, $3^{\mathrm{a}}$ edición, 1754-1764, imprenta de Antonio Marín), ${ }^{62}$ la Crónica de España de Florián de Ocampo -aunque está «sin principio ni fin», es decir incompleto-, los Comentarios de la guerra de Espa$\tilde{n} a$ e Historia de su Rey Phelipe V el Animoso de Vicente Bacallar y Sanna, marqués de San Felipe, que narra los acontecimientos sucedidos en la guerra de Sucesión, editados en 2 volúmenes en Génova y la Historia de la conquista de la Nueva España de Antonio de Solís.

En una aproximación a la tipología podemos mencionar títulos muy genéricos del estilo de Anales del mundo desde la creación, de Carlos Martell (Zaragoza, 1662), Rapsodia historiarum, de Antonio Cocio Sabellici, Diálogos de varia historia... de España, compuesta por Pedro de Mariz (Coimbra, 1594).

Centrados en países concretos y en algunos monarcas hallamos la Historia del reino de Italia, de Carlos Sigonio (Bolonia, 1580), Enmanuelis regis lusitania, de Jerónimo Osorio (Colonia, 1584), Gustavo Adolfo, rey de Suecia, de Fa-

\footnotetext{
${ }^{61}$ Lusitano, médico de Cámara, lector ordinario de Artes, que fue de la universidad de Salamanca, y en la de Coimbra sustituto de la cátedra de Avicena, y después primero electo para la cátedra de práctica de Medicina en dicha Universidad.

${ }^{62}$ En el inventario se escribe textualmente fray Enrique Flórez, doctor y catedrático de Teología de la Universidad de Alcalá y ex Provincial de Castilla. Clave Historial «con que se abre la puerta a la Historia Eclesiástica y Política; descubriendo las cifras, la cronología y frases de la Historia para el fácil manejo de los historiadores; con la cronología de los Papas y Emperadores y breve apuntamiento de sus vidas; todos los reyes de España, Italia y Francia, con los orígenes de todas las monarquías; concilios y sus motivos; herejes y sus errores; santos y escritores clásicos; con los sucesos memorables de cada siglo». «A el mismo número se agregan dieciocho tomos de dicho autor... su edición empieza el año de 1754 y llega sucesivamente hasta el 1764».
}

Hispania Sacra, LXIII

127, enero-junio 2011, 41-74, ISSN: 0018-215-X 
bricio Pons de Castelvi, caballero de Santiago, señor de Masricat y doctor en Leyes (Madrid, 1648), De rebus gestis Ludovici XI, escrita por Juan Sleidano (París, 1545) aplicada a glosar las hazañas del monarca.

Hay, por último, un grupo heterogéneo en el que tienen cabida los Comentarios de Rasis, de Arculano, Floro histórico...que cuenta la guerra contra los turcos (1686), de Francisco Fabro Bremundam del Consejo de S.M. y su Secretario de Lengua Latina en la Secretaría de Estado del Norte, del rey don Rodrigo de Miguel de Luna, ${ }^{63}$ la Historia de Francisco Álvarez de Toledo compuesta por José Vicente de Rustant en 1751 sobre la vida del duque de Alba y dedicada al duque de Huéscar o el ambiguo Historias prodigiosas y maravillosas, de Andrés Piscioni, (Valladolid, 1586).

Pueden incorporarse en este apartado composiciones, que, no siendo trabajos propiamente de ciencia histórica, pueden ser útiles para el historiador a la hora de conocer algún episodio concreto o alguna circunstancia peculiar. Me refiero a títulos como Relación del auto de fe celebrado en Madrid en 1680 escrita por José del Olmo ${ }^{64}$ o el cuaderno titulado Fiestas literarias con motivo de la entrada de la familia real en la corte en 1760.

Como apunté al principio, la historia de la Iglesia está presente en la biblioteca de los colegiales oropesanos, pues se trata de un centro de la Compañía, entidad cualificada del estamento eclesiástico. En ella caben obras de carácter muy genérico y poco profundas, con un tratamiento superficial, del estilo de Annales eclesiastici, de Enrique Spondano, la Historia eclesiástica de España, del tesorero de la catedral de Málaga Francisco de Padilla o la Tabula cronológica status ecclesia católica, de Jacobo Gaulterio, Chronica ecclesia et monarchiarum a condito mundo, de Sebastián Verronio (Friburgo, 1599) a otras muy específicas como Ecclesiastice historiae gentis anglorum, de Beda, o las Relaciones del cardenal Bentivolio, escritas por Francisco de Mendoza y Céspedes, pasando por composiciones en forma de compendios o crónicas destinadas a relatar la historia de otras órdenes religiosas escritas por miembros de ellas, como los franciscanos (Juan de Santa María), los carmelitas (Tomás de Jesús, Miguel

${ }^{63}$ Miguel de Luna, vecino de Granada, interprete del rey Felipe traduce de la lengua arábiga $L a$ verdadera historia del rey don Rodrigo «en la cual se trata la causa principal de la pérdida de España y la conquista que de ella hizo Miramamolín Almanzor, rey que fue de África y de las Arabias. Compuesta por el sabio alcalde Abulcacín Tarif Abentariq, de nación árabe y natural de la Arabia Petrea».

${ }^{64}$ José del Olmo, Alcaide y Familiar del Santo Oficio, Ayuda de la Furriela de S.M. y Maestro Mayor del Buen Retiro y Villa de Madrid. Relación histórica de auto general de fe, «que se celebró en Madrid este año de 1680 con asistencia del Rey N.S. y de las Majestades de la Reina N.Sra. y la Augustísima Reina Madre, siendo Inquisidor General Diego Sarmiento de Villadares. «Refiérense con curiosa puntualidad todas las circunstancias de tan glorioso triunfo de la Fe, con el catálogo de los señores que se hicieron Familiares, y el sumario de las sentencias de los reos. Va inserta la estampa de toda la perspectiva del teatro, plaza y balcones». 
de la Fuente), los eremitas descalzos (Luis de Jesús), los dominicos (Hernando de Castillo) o los benedictinos (Antonio Yepes).

La presencia de la Compañía de Jesús en Asia Oriental y el deseo de ensalzar su labor misionera en tierras extrañas explican la existencia de obras, la mayoría escritas por miembros de la Compañía, testigos de muchas de las peripecias que narran, como las de Luis de Guzmán, Cristóbal Suárez de Figueroa o Andrés Pérez de Rivas ${ }^{65}$ la de Fernando Guerreiro redactada en portugués, ${ }^{66}$ sobre las misiones en China, India y Japón, las de los padres Pedro Murillo Velarde, cuyo libro se publicó en Manila en 1749, y la de Francisco Cambes, centradas en la provincia de Filipinas, o la de Jerónimo Herrán sobre las reducciones de Paraguay (Madrid, 1726), publicada en un momento de efervescencia y tensión entre Portugal, la Santa Sede y España sobre su labor en tierras sudamericanas.

A ilustrar las excelencias de la orden y con idéntico título Historia Societatis Iesus escribieron Nicolás Orlandino, José Juvencio, Francisco Sacchino en 5 vols. todas ellas en formato de folio fueron publicadas en Roma. Están además la conocida Chrono Historia de la Compañía de Jesús en la provincia Toledo (Madrid, 1710) de Bartolomé Alcázar, profesor en el Colegio Real de Madrid, y la de Lorenzo Ortiz que aborda el origen de la institución. No faltan episodios puntuales significativos exclusivamente en la vida interna jesuita como la Relación de venida de los reyes al colegio inglés de Valladolid, compuesta por Antonio Ortiz en 1600.67

En suma, salvo honrosas excepciones nos encontramos con obras que, en gran medida, se aproximan más a la devoción y a la piedad, a la hagiografía, cuando no a la autocomplacencia, que a la historia rigurosa y a un conocimiento que permita elevarse por encima de lo inmediato y que trascienda de las estrechas miras y del riguroso encasillamiento que supone pertenecer a una orden religiosa y al estado eclesiástico.

\footnotetext{
${ }^{65}$ Jesuita provincial en la Nueva España, natural de Córdoba, escribió Historia de los triunfos de nuestra santa fe entre gentes las más bárbaras y fieras del nuevo orbe, conseguidos por los soldados de la milicia de la Compañía de Jesús en las misiones de la Provincia de la Nueva España. «Refiérense asimismo las costumbres, ritos y supersticiones que usaban estas gentes, sus puestos y temples; las victorias que de algunas de ellas alcanzaron con las armas los católicos españoles cuando les obligaron a tomarlas, y las dichosas muertes de veinte religiosos de la Compañía, que en varios puestos y a manos de varias naciones dieron sus vidas por la predicación del Santo Evangelio».

${ }^{66}$ Sobre este idioma tiene la biblioteca unas Curiosas advertencias de boa gramatica escritas por Bartolomé Rodríguez Chorro y publicadas en Lisboa en 1619.

${ }^{67}$ Los jesuitas establecieron dos «colegios ingleses» en España, uno en Valladolid y otro en Sevi1la. Federico Eguiluz Ortiz De LATIERRo, «La fundación del colegio inglés de Valladolid», Revista de Filología Inglesa, núm. 10 (1980), pp. 131-177; Martín MuRPHY, «Los comienzos del colegio inglés de San Gregorio en Sevilla», Archivo Hispalense LXVII/204 (1984), pp. 3-24.
}

Hispania Sacra, LXIII

127, enero-junio 2011, 41-74, ISSN: 0018-215-X 


\section{Geografía}

Dando cabida dentro de esta denominación a otras disciplinas afines, más o menos relacionadas con ella como pueden ser la astronomía o la corografía, encontramos en la biblioteca algunas obras de renombrada celebridad, siendo quizás la más conocida la Sphera de Juan Sacrobosto. ${ }^{68}$ Junto a ella se pueden mencionar La sfera del mondo, de Alessandro Piccolomini escrita en italiano ${ }^{69}$ (Venecia, 1563), Espejo geográfico, de Pedro Hurtado de Mendoza ${ }^{70}$ (Madrid, 1690) o Strabonis Geographicorum comentarios, de Conrado Heresbachio (Basilea, 1523). Libros de relatos de viajes detallando los territorios por donde transcurren también tienen cabida. Gaspar Barreiros publica en Coimbra su Corographia de algunos lugares, que describe los sitios por los que pasa en un viaje iniciado en 1541 en Badajoz y que termina en Milán. Pantaleón Daveiro se ocupa de Palestina en Itinerario de Tierra Santa e todas sus particular (Lisboa, 1596) y Antonio Herrera de la América hispánica en Novus orbis sive descriptio India occidentalis (Ámsterdam, 1622).

En astronomía cabe mencionar autores como el profesor en la universidad de Bolonia Juan Antonio Magini, De astrología ratione (Frankfurt, 1608), Pedro Baeausardo, Annuli astronomici instrumenti, (París, 1557), Pedro Enguera, Non plus ultra del lunario y pronóstico perpetuo ${ }^{71}$ (Madrid 1728) o un popular Calendario perpetuo. Por último hay que reseñar la existencia de un par de libros de mapas, uno de ellos de Claudio Ptolomeo.

${ }^{68}$ Conservan cinco ejemplares editados en fechas distintas (Venecia, 1546; París 1549, 1561; Lyon 1564, 1567). En el registro correspondiente a Juan Atrociano Amilius macer de herbarium virtutibus (Basilea, 1527) se aclara que «tiene unida otra obrita», De Sphera, de Juan de Sacrobosco impresa en Vitaberga por Josephum Clug en 1531. Esta obra fue escrita en 1220 y se imprimió por primera vez en 1472 .

${ }^{69}$ Aparece un diccionario italiano-latín -Dittionarium o vero Thesoro Lingua volgare e Latinaconfeccionado por Pedro Galefini editado en 1671.

${ }^{70}$ Caballero de Calatrava, Secretario de Cartas del duque del Infantado y Pastrana, Espejo geográfico «contiene la descripción del globo terráqueo así por las divisiones que tiene en él señaladas la naturaleza como por las civiles y arbitrarias en imperios, reinos, repúblicas y otros estados». En el siguiente registro figura el mismo libro, editado un año antes, y se explica «en el cual se descubre, breve y claramente, así lo científico de la Geografía como lo histórico que pertenece a esta tan gustosa como noble y necesaria ciencias. Contiene el tratado de la Esfera y el modo de valerse de los globos con las más modernas observaciones y algunas experiencias físico-matemáticas en lo más curioso de la filosofía». Sobre la relevancia de esta obra véase Víctor NAVARRO BROTONS, «Los jesuitas y la renovación científica en la España del siglo XVII», Studia Histórica. Historia Moderna, 14 (1996), pp. 42-44.

${ }^{71}$ En realidad se trata del «Non plus ultra del Lunario y pronóstico perpetuo general y particular para cada reino y provincia, compuesto por el valenciano Jerónimo Cortés, expurgado según el expurgatorio de la Santa Inquisición de 1707 y ahora nuevamente reformado y añadido por el profesor de matemáticas Pedro Enguera». 


\section{Matemáticas}

Lo que convencionalmente se entiende por «Ciencias» tiene una representación muy insignificante, siendo las matemáticas las que dejan una mayor huella ya sea la aritmética, la geometría u otras disciplinas estrechamente vinculadas a los números, en especial la astronomía pues frecuentemente es cultivada de forma conjunta con las matemáticas.

Llama la atención la docena de registros del jesuita alemán Cristóbal Clavio, matemático y gnomicista, uno de los promotores del calendario gregoriano y el astrónomo más respetado en la Europa de su tiempo, con cinco ejemplares de Operum mathematicorum (Maguncia, 1612) más otras obras de gnomónica Gnomonices (Roma, 1581), geometría, comentarios a Sacrobosco, fabricación y uso de instrumentos y el calendario gregoriano, editadas en Roma, Venecia y Colonia. Otros autores mencionados son Juan Regiomontano, Mathematicii, (Nuremberg, 1544), Juan Pérez de Moya, Aritmética práctica y especulativa, (Madrid, 1609), probablemente el libro de álgebra más divulgado en el Quinientos y que llegó a conocer hasta treintas reimpresiones, Pedro de Ulloa, ${ }^{72}$ Elementos mathemáticos..., (Madrid, 1706), Antich Rocha de Gerona ${ }^{73}$ Aritmética, (Barcelona, 1565), el cosmógrafo Rodrigo Zamorano y su traducción de la Geometría de Euclides, (Sevilla, 1576) y Andrés de Céspedes ${ }^{74}$ Instrumentos nuevos de Geometría, (Madrid, 1606)

Una obra que tuvo cierta resonancia en su momento en el ámbito de las ciencias y que está registrada en el colegio fue la del alcaraceño Sebastián Izquierdo. Pharus scientiarum, (Lyon, 1659) en la que presenta una teoría general de la ciencia en forma de tratado sobre el saber científico y que tuvo una gran influencia. ${ }^{75}$

\footnotetext{
72 Jesuita, catedrático de matemáticas de los Estudios Reales del Colegio Imperial y del Supremo Consejo de Indias. El título completo es Elementos matemáticos que comprenden los principios de la Arte menor y mayor de la Aritmética; los de los planos y sólidos de la Geometría; los esféricos de Teodosio; las principales propiedades de las secciones cónicas; la trigonometría elemental así rectilínea como esférica; la logarítmica, los principios del álgebra y su aplicación a la Geometría. Es autor también de una Música universal o principios universales de la Música.

73 «y de varios autores recopilada; provechosa para todos estados de gentes. Va añadido un compendio para tener y regir los libros de cuentas».

74 Cosmógrafo mayor del Rey, el libro es «muy necesario para medir distancias y alturas sin que intervengan números, como se demuestra en la práctica. Demás de esto se ponen otros tratados, como es uno de conducir aguas, y otro una cuestión de Artillería, en donde se ponen algunas demostraciones curiosas».

75 Víctor NAVARRo BROTONS, «Los jesuitas y la renovación científica...» pp. 29-30.
}

Hispania Sacra, LXIII

127, enero-junio 2011, 41-74, ISSN: 0018-215-X 


\section{Política}

Apenas una decena de ejemplares están asignados a la política, al gobierno de la monarquía, circunstancia, por otro lado, lógica, habida cuenta la naturaleza de la biblioteca y los usuarios a quienes va dirigida. De Juan Carlos Bazán, marqués de San Gil tienen la Miscelánea política ${ }^{76}$ en castellano y francés, ${ }^{77}$ Oeuvres politiques, historiques et morales, de Pedro de Navarra y de la Cueva, caballero de la orden de Santiago, marqués de Cábrega, mayordomo de la Reina, Logros de la monarquía con aciertos de un valido (Madrid, 1669), Obras y días. Manual de señores y príncipes del prolífico Juan Eusebio Nieremberg, la clásica de Francisco de Quevedo Política de Dios y Gobierno de Cristo, «sacada de la Sagrada Escritura para acierto del Rey y reino en sus acciones», o el no menos clásico de Saavedra Fajardo Idea de un príncipe político cristiano del que poseen tres ejemplares, dos editados en Madrid y uno en Ámsterdam en 1775, 1766 y 1764 respectivamente. Sobre el gobierno del Nuevo Mundo está la Política indiana, de Francisco Ramiro de Valenzuela ${ }^{78}$ (Madrid, 1736). De carácter genérico son los Discursos políticos, de Pedro Fernández Navarrete (Barcelona, 1621).

\section{Derecho}

Hay textos jurídicos, de derecho civil y canónico, aunque no muchos. La razón es el carácter pleitista de la sociedad y la necesidad de los jesuitas de documentarse para hacer frente a los conflictos legales de carácter civil o

\footnotetext{
${ }^{76}$ La saca a la luz su nieto y heredero don Joaquín Antonio Bazán y Melo, del Consejo, su oidor de Valladolid, corregidor de Vizcaya...» añadiendo los epílogos de tratados de paces hasta 1731 y lo principal ocurrido hasta $1741 »$.

${ }^{77}$ En la biblioteca aparece una Gramática compuesta por Pedro Pablo Billet y publicada en Madrid en 1688 y un diccionario de francés-alemán de Levinus Hulsio (Aoppenheim, 1614).

${ }^{78}$ Aunque aparece asignada a este autor en realidad se trata de la obra «compuesta por el Dr. D. Juan de Solórzano Pereira, caballero de Santiago del Consejo de Castilla y de Indias. Dividida en seis libros, en los cuales con gran distinción y estudio se trata y resuelve todo lo tocante al descubrimiento, descripción y adquisición y retención de las mismas Indias y su gobierno particular; así cerca de las personas de los indios y sus servicios tributarios diezmos y encomiendas, como de lo espiritual y eclesiástico cerca de su doctrina, patronazgo, reales iglesias, prelados, prebendados, curas seculares y regulares, inquisidores, comisarios de cruzada y de las religiones. Y en lo temporal cerca de los magistrados seculares, virreyes, presidentes audiencias, Consejo Supremo y Junta de Guerra de ellas, con inserción y declaración de las muchas cédulas reales que para esto se han despachado. Obra de sumo trabajo y de igual importancia y utilidad no solo para los de las Indias sino de las de España y otras naciones (de cualquier profesión que sean) por la gran variedad de cosas que comprende, adornada de todas letras y escrita con el método, claridad y lenguaje que por ella parecerá. Con dos índices muy distintos y copiosos, uno de los libros y capítulos en que se divide y otro de las cosas notables que contiene. Sale en este tercera impresión ilustrada por el licenciado don Francisco Ramiro de Valenzuela».
} 
eclesiástico y de ámbito público o privado. Son básicamente textos clásicos, como Partidas de Alfonso X y Ordenanzas reales de Castilla, (Toledo, 1551) en la edición de Montalvo. Están el Codici Justiniani, con comentarios de Cujacio y de Charondas, y una compilación en seis volúmenes de tipo folio de las Leyes del reino y un elenco de Disputationes, de Sententiarum, destacando las de Pedro Lombardo, seis tomos editados en París y Lyon en varios años del siglo XVI con la singularidad de que su Thesaurus magistri sententiarum/Opus singulare, se publicó en Venecia en fecha tan temprana como 1492 en los talleres tipográficos de «Simonis, alias Bevilaqua Papien». Se encuentran Commentarii a las mismas del franciscano Juan de Ovando y del dominico Domingo de Soto, uno de los nombres con más obras en la biblioteca, dos decenas.

Un título recurrente y muy utilizado por los juristas, el De justitia et jure se repite hasta en trece ocasiones, si bien los autores son distintos: Pedro de Aragón, Martín Becano, Domingo Soto, ${ }^{79}$ Leonardo Lessio, Luis Molina y Gaspar Hurtado. No menos conocidos son los tratados De rege et regendi, de Mateo López Bravo y De rege et regis institutione, de Juan de Mariana.

En derecho canónico están las Constituciones sinodales de Ávila y Toledo, Constituciones y Reglas de la Compañía de Jesús, libros que recogen las disposiciones del concilio de Trento, abundantes Decretales, de Martín de Azpilcueta, Diego Covarrubias, Panormitano, y numerosas Summas de concilios y de pontífices y algún texto monográfico en seis volúmenes sobre Forum ecclesiasticorum, del doctor en teología y cánones Pedro Leurenio. Hay un cuaderno titulado Memorial al rey sobre jurisdicción de los religiosos de la Compañía de Jesús. Si bien su contenido es variado tal vez tenga cabida en este apartado el conocido título de Juan de Hevia Bolaño Curia filipica ${ }^{80}$ (Valladolid, 1609). Aquí tendría sitio el Index expurgatorius hispanus de 1707 del inquisidor general Diego Sarmiento Valladares.

Casi de modo testimonial y en cierta manera como «rarezas» en el conjunto de la biblioteca de San Bernardo son la Invención liberal y arte del juego del ajedrez, de Ruiz López de Sigura (Alcalá, 1561), el Estilo y método de escribir cartas, de Juan Vicente Peliger (Madrid, 1619, imprenta Juan de la Cuesta), Música univer-

\footnotetext{
${ }^{79}$ Aunque en media docena de veces aparece De justitia et jure corresponden a ediciones diferentes, todas editadas en Salamanca o en Medina del Campo entre los años 1553 y 1589 y en los talleres de Andréas de Portonariis, Joannis Baptista de Terranova, Joannis Mariam de Terranova y Joannis Moreni de la ciudad del Tormes y Franciscus de Canto de la villa vallisoletana. Una situación casi calcada podemos indicar respecto a los quince tomos de Commentariorum...in quartum sententiarum. De Domingo de Soto se recogen otros títulos que tienen que ver con estudios sobre Aristóteles y las epístolas de san Pablo.

80 «donde se trata breve y compendiosamente de la mercancía y contratación de tierra y mar, útil y provechoso para mercaderes, negociantes, navegadores y sus consulados, ministros de los juicios, profesores de derechos y otras personas». Está dedicada a Pedro Amezqueta del Consejo de Su Majestad, Presidente de Alcaldes del Crimen en la Real Chancillería de Valladolid.
} 
sal o principios universales de música, de Pedro de Ulloa al que ya se ha citado como escritor de un libro de matemáticas (Madrid, 1717), Elementos de toda la arquitectura civil, del jesuita Cristiano Reger, Cosmógrafo Mayor del rey y del Consejo de Indias, traducido del italiano por el padre Miguel de Benavente, maestro de Matemáticas en el Colegio Imperial (Madrid, 1763), la célebre y meritoria Agricultura, de Gabriel Alonso de Herrera, publicada en dos volúmenes en Medina del Campo en 1568 y 1584 por Francisco del Campo o el Lignum plantarum secus decursus aquarum, fructum, de Pedro Ciruelo (Alcalá 1521).

$\mathrm{Al}$ examinar el contenido de esta librería, se han citado y comentado reiteradamente, pero queremos, aunque sea muy brevemente, señalar los autores cuya presencia en volúmenes era más ostensible en los anaqueles de la biblioteca. A la cabeza de todos se encuentra Tomás de Aquino cuya prolífica obra supera los 50 tomos, el jesuita Francisco Suárez con medio centenar se sitúa muy cerca, seguidos de Gabriel Vázquez, jesuita (43) y del clásico Aristóteles (41). Con más de treinta volúmenes figuran los frailes de la orden de Predicadores Luis de Granada y Domingo de Soto, más los jesuitas Antonio Rubio y Francisco Toledo, ambos especialistas en el pensamiento aristotélico.

Otro dato relevante es el contingente de 246 padres jesuitas, ${ }^{81}$ un tercio del conjunto. A la vista de la temática eminentemente religiosa proliferan frailes de otras órdenes con fuerte tradición intelectual en el campo de la filosofía y teología sobre todo los dominicos y agustinos, franciscanos, en sus diferentes ramas, jerónimos y carmelitas.

Hecho el pormenorizado análisis del contenido de la biblioteca de Oropesa, hay que preguntarse, como esbozábamos al inicio del epígrafe, dónde está la literatura. La respuesta es: en ningún sitio ${ }^{82}$ ¿Cómo explicar esa ausencia? La temática de las obras es abrumadoramente religiosa con ninguna concesión a la literatura de evasión y muy poca a la ciencia. En la regla 47 del colegio se prohíbe las obras de caballerías o de «aficiones». Es además lógico que proliferen sesudos tratados, en latín por supuesto, de asuntos que tienen que ver con el objeto de estudio a que se dedican, pero que en una biblioteca tan completa en número, como la que se analiza, no aparezca ni un solo libro de lo que comúnmente llamamos literatura, invita a la reflexión y plantea preguntas sobre el tipo de educación

\footnotetext{
${ }^{81}$ Muy útil la consulta del Diccionario Histórico de la Compañía de Jesús. Biográfico-Temático, Madrid, 2001.

${ }^{82}$ Hay una obra de Lope de Vega, Jerusalén conquistada, cuya título ya roza lo religioso y que curiosamente está «sin portada ni fin». Es cierto que aparecen autores de gran reconocimiento en el mundo de las letras como Teresa de Jesús, Luis de León o Luis de Granada, pero no lo están en cuanto creadores de literatura sino por su vertiente piadosa. Algo parecido podríamos señalar con Luis de Camoes y su Os lusiadas, (Lisboa, 1609) o con Benito Jerónimo de Feijoo y su monumental Teatro crítico universal, (Madrid, 1733).
} 
recibida, que, en ningún caso, parece integral dado el menosprecio o desprecio hacia géneros y autores literarios cuya categoría nadie pone en entredicho, aunque entonces sí. Parece que en aquella atmósfera rigorista había pocas ventanas abiertas al ocio, a la recreación saludable; demasiados peligros amenazaban la existencia en esta carrera hacia la trascendencia con claro rechazo a todo lo terrenal. Es, en suma, un ejemplo de excesivo ascetismo.

Estaban tan preocupados por vigilar las lecturas que, entre las denuncias contra un rector de San Bernardo está la de «el poco cuidado en visitar los libros que los colegiales tienen, siendo algunos profanos». Fue amonestado. ${ }^{83} \mathrm{Si}$ nos fijamos en el paradigma educativo de la Compañía de Jesús, su fundador escribió que su aspiración era fundir «la virtud con las letras, la vida con la ciencia, la conducta con el saber». Por eso habría que matizar lo que interpreta como letras y ciencia o bien admitir que la idea fundacional iba por un lado y la realidad por otro. O que, veintidós años después de la muerte del fundador, esta orientación estaba en desuso.

\section{OTROS ASPECTOS}

La información de que disponemos permite abordar cuestiones, que contribuyen a arrojar luz sobre algunos puntos que difícilmente encontraremos en otra clase de documentación, como los protocolos notariales, que no recogen datos de tanto interés para la historia de la cultura escrita.

\section{FORMATO}

En el gráfico que presentamos se aprecia un predominio claro de los libros de gran tamaño, en particular los de tipo folio (36 por ciento), seguido de los de cuarto (30) y octavo (26).

\section{Estado físico de los libros}

Con inusitada frecuencia se acompaña la información sobre los libros con observaciones sobre su descripción o estado físico, de tal suerte que abundan comentarios que aluden a la portada - «muy borrada y confusa», «remendada»o su inexistencia, al título -«con la mitad del título roto»- o a otras particularidades tales «sin principio, fin ni forro», «sin foliatura ni principio» «muy descuadernado», «roto», «forrado de cabritilla roja», «forrado en pergamino». Muchísimo más corriente es la referencia a obras «de marca»-152- o «de pasta» -185-, «de marca en pasta $-18-$, «de media marca». A veces tasan el pliego.

${ }^{83}$ A.H.N. Sección Nobleza. Frías C.1290, D. 23.

Hispania Sacra, LXIII

127, enero-junio 2011, 41-74, ISSN: 0018-215-X 


\section{FORMATO DE LOS LIBROS}

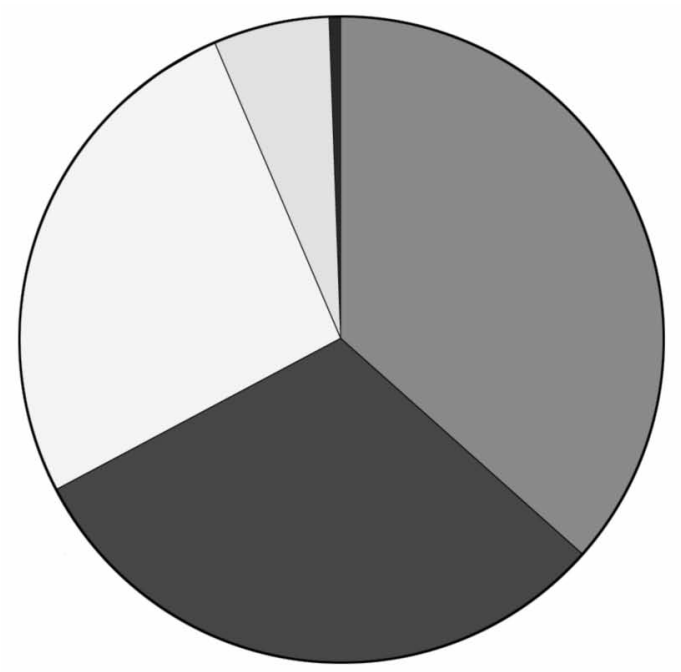

\begin{tabular}{|l|}
\hline FOLIO \\
$\square$ CUARTO \\
$\square$ OCTAVO \\
$\square$ DOZAVO \\
$\square$ SIN ESPECIFICAR
\end{tabular}

\section{Dedicatoria}

Aunque no tiene ninguna relevancia especial a la hora de fijar las peculiaridades de esta biblioteca, parece oportuno anotar la tipología de dedicatorias que se exhiben en numerosas obras (389), pues no debemos desdeñar la información. Es sabido que detrás de una dedicatoria se halla con frecuencia una labor de mecenazgo, de gratitud o de devoción religiosa.

Toda la Casa de Austria aparece citada bien en forma de reyes (33 libros), reinas, príncipes, princesas o infantas. La grandeza de Castilla es objeto de permanente gratitud, duques (31), marqueses (29) y condes (21) al igual que otros señores de menor relieve. Proliferan cardenales (48), obispos (39) y arzobispos (24) y otros miembros encumbrados del clero regular -abadesas, prioras-y hay textos dedicados a los papas. Se menciona al nuncio, a los cabildos catedralicios, deanes, chantres o canónigos, a los capellanes y a frailes.

Se alude a personas con cargos elevados en Consejos o virreinatos o a miembros del Santo Oficio. Hay dedicatorias muy espirituales, en especial las que tiene como referencia a la Virgen María, en sus diversas advocaciones, cerca de la veintena, al Santísimo Sacramento, la Trinidad, ${ }^{84}$ Jesucristo, santos canonizados.

${ }^{84}$ Agustín de Castejón dedica sus Sermones «a toda la razón de su esperanza, todo el imán de su afecto y toda la adoración de sus potencias y sentidos, la Santísima Trinidad, Padre, Hijo y Spiritu Santo, tres personas distintas y un solo Dios verdadero». 
Completan la nómina comendadores y caballeros de órdenes militares, generales de los ejércitos, embajadores, incluso un autor dedica su composición al padre. Como curiosidad, hay una dedicatoria a Lope de Vega Carpio en el libro de Francisco Herrera Maldonado ${ }^{85}$ Sanazaro español, (Madrid, 1620).

\section{Lugares de edición}

El mercado editorial ${ }^{86}$ se encuentra nítidamente dominado por dos ciudades, Lyon (478 libros) y Madrid87 (397), seguidos a cierta distancia por Alcalá de Henares (178), París (176), Salamanca (166) y Venecia ${ }^{88}$ (114). Relevante es asimismo la fuerza de otras poblaciones con tradición editorial como Amberes (94) o Roma (82). En España, además de las ya mencionadas, cabe citar Valladolid, Valencia, próximas a las cuarenta obras publicadas, y Sevilla, Zaragoza y Medina del Campo que superan la veintena.

Parece también fuera de toda duda la existencia de una activa circulación de libros por Europa, hasta de lugares poco habituales como Cracovia, Praga o en España, Baeza, Olite, Tarazona. Contamos con alguna muestra de prensas del Nuevo Mundo, en México, la de Agustín de Santistevan y Francisco Lupercio que publican en 1661 un libro sobre san Francisco Javier escrito por Matías de Peralta Calderón, y de Manila donde Nicolás de la Cruz Bagay imprime en 1749 una Historia de la provincia de Filipinas compuesta por Pedro Murillo.

\footnotetext{
${ }^{85}$ Natural de Oropesa, fue prior de la Encomienda de Villalba del hábito de san Juan y canónigo de la Santa Iglesia Real de Arbas de León. En el Sanazaro español explica «los tres libros del Parto de la Virgen Nuestra Señora. Traducción castellana de verso heroico latino». Del mismo autor se tiene Vida y maravillosas virtudes de el siervo de Dios Bernardino de Obregón, padre y fundador de la Congregación de los enfermos pobres y autor de muchas obras pías de Madrid y otra partes, al igual que dos títulos que tienen que ver con China: Epítome historial del reino de la China (Madrid, 1621) y Peregrinaciones de Fernán Méndez Pinto a Oriente, Madrid, 1650. Esta última está dedicada al conde de Oropesa, sin duda por razones de paisanaje.

${ }^{86}$ Henri-Jean MARTIN, «La circulación del libro en Europa y el papel de París en la primera mitad del siglo XVII», en Armando PetruCCI, Libros, editores... pp. 119-168.

${ }^{87}$ Igualmente en el colegio de Salamanca, la capital del reino aparece con un protagonismo editorial sobresaliente. Margarita BECEDAs GonZÁLEZ y Oscar LILAO FRANCA, «Noticias sobre la biblioteca del Colegio Real de la Compañía de Jesús de Salamanca», en Homenaje al Padre Benigno Hernández. Montes, Salamanca, Diputación, Ayuntamiento, Universidad, Caja Duero, 1999, p. 24

${ }^{88}$ Se conocen casi 500 nombres de tipógrafos-editores-libreros venecianos que hicieron más de 7.000 ediciones. Amedeo QuONDAM, «Mercancía de honor, mercancía de utilidad. Producción del libro y trabajo intelectual en Venecia en el siglo XVI», en Armando PeTRUCCI, Libros, editores... p. 76.
}

Hispania Sacra, LXIII

127, enero-junio 2011, 41-74, ISSN: 0018-215-X 


\section{Lugares de edición}

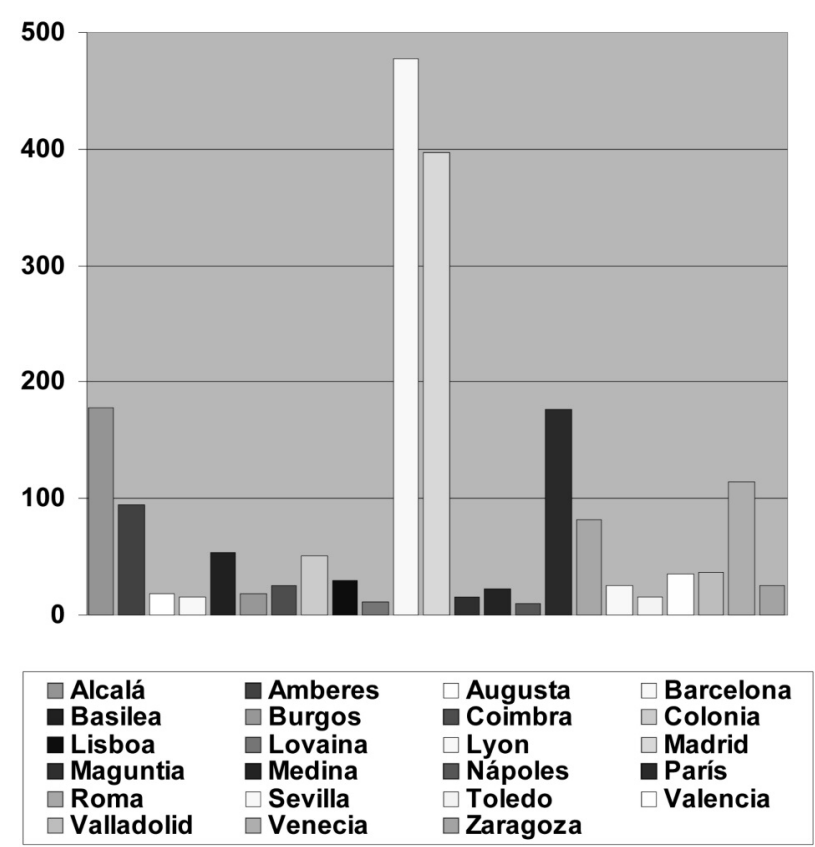

\section{Editores}

En algo más de 300 libros se especifica «a costa» o «a expensis» de quien corría a cargo la edición así como la librería, la casa o el lugar donde se podían adquirir. Bajo el apelativo de maestro librero, mercader de libros, o menos frecuente, librero de Su Majestad, librero en Corte o librero de Cámara, desfilan numerosos personajes de los que, sobre todo en Madrid, se dan detalles minuciosos. Manuel López, Gabriel León, Francisco Robles son constantemente citados con las localizaciones exactas donde tenían sus establecimientos, Puerta del Sol, calle Mayor «frente a San Felipe», Toledo. Precisamente en torno a esta vía estaban ubicados varios libreros (Lorenzo de Ibarra, Juan de San Vicente, Santiago Martín, Dionisio Ortega, Francisco Ortega, Juan Antonio Bonet), así como en Atocha, Mayor o el propio Palacio.

No sólo de la capital de la monarquía hispánica contamos con información. Se recogen datos de París con la múltiples veces nombrada «vía Jacobea» o «vía ad Divum Jacobum» y la «vico Bellovaco», de Lyon se menciona la «vía Mercato- 
ria», de Barcelona la calle Condal y las plazas del Ángel y San Jaime, de Valladolid Samano, de Sevilla Génova, de Valencia Caballeros y las plazas de la Seo y de la Hierba, en Zaragoza Cuchillerías... Algunas veces se aclara que las obras se venden en colegios jesuitas (San Vicente Ferrer en Zaragoza, imperial de Madrid), junto a los Estudios de la Compañía, en el Seminario de Roma.

\section{Años de edición}

A la vista de la tabla y del gráfico que presentamos resulta notorio que la mayoría de los libros que configuran la biblioteca jesuítica de Oropesa se publicaron entre la segunda mitad del Quinientos y la primera de la centuria siguiente.

\begin{tabular}{|lrlrll|}
\hline Siglo XVI & $\mathbf{N}^{\mathbf{0}}$ & Siglo XVII & $\mathbf{N}^{\mathbf{o}}$ & Siglo XVIII & $\mathbf{N}^{\mathbf{0}}$ \\
\hline $1488-1500$ & 9 & $1601-1610$ & 207 & $1701-1710$ & 23 \\
\hline $1501-1510$ & 10 & $1611-1620$ & 272 & $1711-1720$ & 35 \\
\hline $1511-1520$ & 22 & $1621-1630$ & 144 & $1721-1730$ & 37 \\
\hline $1521-1530$ & 56 & $1631-1640$ & 68 & $1731-1740$ & 39 \\
\hline $1531-1540$ & 71 & $1641-1650$ & 76 & $1741-1750$ & 20 \\
\hline $1541-1550$ & 108 & $1651-1660$ & 77 & $1751-1760$ & 31 \\
\hline $1551-1560$ & 179 & $1661-1670$ & 44 & $1761-1768$ & 10 \\
\hline $1561-1570$ & 222 & $1671-1680$ & 34 & & \\
\hline $1571-1580$ & 155 & $1681-1690$ & 26 & & \\
\hline $1581-1590$ & 221 & $1691-1700$ & 44 & & $\mathbf{1 9 5}$ \\
\hline $1591-1600$ & 169 & & & & \\
\hline Total & $\mathbf{1 . 2 2 2}$ & Total & $\mathbf{9 9 2}$ & Total & \\
\hline
\end{tabular}

Ediciones cada 10 años (1488-1768)

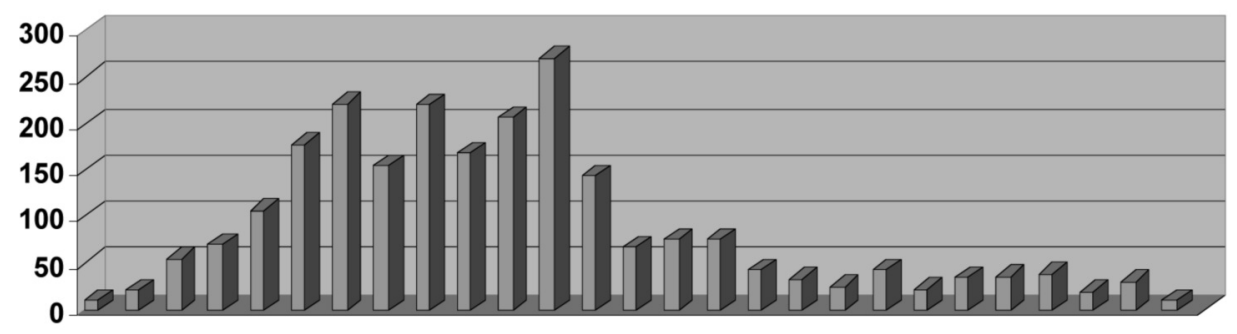

Hispania Sacra, LXIII

127, enero-junio 2011, 41-74, ISSN: 0018-215-X 
En una distribución temporal más compacta, por periodos de 25 años notamos que la mayor concentración se produce entre 1551 y 1625, con algo más del $65 \%$ de todos los libros publicados.

Siete son los títulos editados en los años finales del siglo XV, correspondiendo la mayor antigüedad a la obra Medicina de varios autores que fue publicada en Bononia en 1488 en folio y pasta por Henricum de Arlem et Joannem Valbecld. 89

\section{Idiomas}

Como no podía ser de otra manera, el latín es la lengua hegemónica por su carácter de lengua culta y por ser el modo habitual de comunicación dentro de los colegios de la Compañía cuyas constituciones recogen la obligatoriedad de que sus estudiantes se expresen en ella tanto en la vida académica como en las actividades ordinarias. Con 1.900 registros supone el $80 \%$ de todas las obras. En castellano hay 453, un 19\%,90 repartiéndose el 1\% restante casi de forma testimonial entre libros escritos en hebreo (19) griego (8), portugués (6), italiano (4) y francés (2).

En síntesis y a modo de balance final podemos concluir señalando que la biblioteca de san Bernardo era rica en volúmenes, vertebrada alrededor de la Teología y la Filosofía, con dos figuras hegemónicas, Aristóteles y Tomás de Aquino, más un contingente significativo de obras de Medicina -cuya existencia probablemente halla que poner en conexión con el hospital de San Juan Bautista de la localidad, tutelado por la Compañía de Jesús-, de autores clásicos, un desprecio manifiesto hacia la literatura y un olvido de las ciencias experimentales, con lo cual el ideal ignaciano de formación integral definido en la Ratio studiorum quedaba en una vaga declaración de principios.

Biblioteca escrita, en su inmensa mayoría por miembros del estado eclesiástico, ${ }^{91}$ en especial por religiosos de las órdenes con mayor tradición intelectual

\footnotetext{
${ }^{89}$ Las otras seis corresponden a Pedro Lombardo Thesaurus magistri sententiarum/Opus singulare, Venecia, 1492; la Medicinis de Avicena en el mismo lugar y fecha; Schedel Hartmano Registrum huius operis libri Cronicarum, (1493); Felipe Beroaldo Annotatione centum, Brijia, 1496; otras dos publicadas en Venecia Opus pandectarum de Mateo Silvático (1498) y una Summa de exemplis de 1499.

${ }^{90}$ Aunque la jerarquía sigue siendo la misma los porcentajes son diferentes respecto a los que señala José Luis Betrán, 64 para latín y 39 para el castellano, sin duda porque el conjunto de la biblioteca potosiana es claramente inferior a la de Oropesa. José Luis BETRÁN MOYA, «Bibliotecas de Ultramar...»,p. 311 .

${ }^{91}$ Un estudio exhaustivo sobre el clero y los libros puede verse en Ramón SÁNCHEZ GonZÁLEZ, «La cultura de las letras en el clero capitular de la catedral toledana» en Sociedad y elites eclesiásticas en la España moderna, Cuenca, Universidad de CLM, 2000, págs. 163-236.
} 
-dominicos, agustinos- y, por supuesto jesuitas, sujetos y objetos prioritarios de atención para el colegio oropesano de san Bernardo. No obstante, conviene resaltar el extraordinario peso del clero en la vida intelectual de la época, cuya influencia va mucha allá de los estrechos márgenes de la Compañía de Jesús, impregnando su pensamiento y sus ideas casi todas las ramas del saber y haciendo notar su presencia en los centros educativos, desde los más humildes hasta los más encumbrados, como los universitarios e incluso los más elitistas. Necesario es también reflexionar sobre el contenido de las ideas expuestas, sobre su rigor científico o intelectual ya que, con cierta frecuencia, al lado de valiosas aportaciones en los campos de la espiritualidad, la religiosidad o la vida pastoral, se caía en descaradas hagiografías, exaltaciones desmesuradas en las narraciones de las crónicas de sus órdenes, dando rienda suelta a la imaginación.

La biblioteca, que la Compañía de Jesús tenía en la villa toledana de Oropesa, por su riqueza en obras y nombres, es comparable con otras de la misma orden. Esto puede contribuir a un mejor y más completo conocimiento de los patrimonios bibliográficos en manos de los jesuitas. La conservación del inventario permite vislumbrar los pormenores de la «librería», pero no del destino de esos libros, cuyo paradero definitivo ignoramos, aunque algunos indicios nos hacen temer que hayan desaparecidos. Las noticias expresadas al principio de que algunos lugareños construían zambombas con los pergaminos y libros propiedad del conde y del uso de hojas de papel para encender fuego no alimentan el optimismo, pero estimulan la necesidad de transmitir el respeto y el amor por los libros. 